(C) <2021>. This manuscript version is made available under the CC-BY-NC-ND 4.0 license http://creativecommons.org/licenses/by-nc-nd/4.0/

The definitive publisher version is available online at https://doi.org/ 10.1016/j.jwpe.2021.102268 


\title{
Ultrasound-assisted membrane technologies for fouling control and performance improvement: A review
}

\author{
Osamah Naji ${ }^{1}$, Raed A Al-juboori ${ }^{2,3}$, Abdulaziz Khan ${ }^{1}$, Sudesh Yadav ${ }^{1}$, Ali Altaee ${ }^{1 *}$, Alla \\ Alpatova $^{4}$, Sofiane Soukane ${ }^{4}$, Noreddine Ghaffour ${ }^{4 *}$ \\ ${ }^{1}$ Centre for Technologies for Water and Wastewater, School of Civil and Environmental Engineering, \\ University of Technology Sydney, 15 Broadway, NSW, 2007 \\ ${ }^{2}$ Water and Environmental Engineering Research Group, Department of Built Environment, Aalto \\ University, P.O. Box 15200, Aalto FI-00076, Espoo, Finland \\ ${ }^{3}$ Faculty of Health, Engineering and Sciences, University of Southern Queensland, Toowoomba 4350, \\ Australia \\ ${ }^{4}$ King Abdullah University of Science and Technology (KAUST), Water Desalination and Reuse Center \\ (WDRC), Biological and Environmental Science and Engineering (BESE), 23955-6900 Thuwal, Saudi \\ Arabia
}

\section{Abstract}

Membrane separation is widely used in wastewater treatment and desalination due to its high performance and ability to handle feed solutions of different qualities. Despite vast history of success, membrane fouling remains a major system deficiency that imposes substantial process limitations by reducing permeate production and increasing energy demand. Besides, chemical cleaning-in-place (CIP) adversely affects membrane integrity and generates an extra waste stream. Ultrasound (US) is a relatively new cleaning technique that improves process performance by mitigating fouling accumulation at a membrane surface and improving permeate flux by promoting mass and heat transfer. US-assisted membrane processes is an efficient method for fouling reduction and significant flux improvement. This study comprehensively reviews US applications in pressure-, thermally- and osmotic-driven membrane technologies and their impact on process performance. It also explores the impact of US operating conditions on membrane separation properties and how these parameters can be tuned to achieve the desirable outcome. To date, the application of US in membrane technologies is limited to laboratory tests. In the authors opinion, there is a niche market for 
32 US-assisted membrane technology in heavily contaminated water such as wastewater and brine. After critical analysis of the literature, we found that there are still several aspects of the process need to be scrutinized carefully to make an adequate evaluation of its feasibility on an industrial scale. The most urgent one is the techno-economic evaluation of the technology based on large-scale and long-term tests. The study proposed a set of recommendations for future research directions of US applications in membrane technologies.

Keywords: Ultrasound, Pressure-driven membrane technologies, Emerging membrane technologies, Fouling mitigation, Flux improvement.

\section{Introduction}

Population increase and rapid industrial development imposed additional demand on freshwater resources $[1,2]$. Although developed countries enjoy good quality water provided by centralized municipal water supply systems, safe drinking water remains scarce in developing countries. Contaminants in drinking water are among the most significant issues, and millions of people suffer from their hazardous effects. Different filtration processes and adsorption processes were applied for water cleaning and contaminants removal [3]. Membrane-based processes are increasingly applied to overcome water shortage and produce high-quality drinking water by separating water molecules from contaminants. Different types

51 of pressure-driven membrane processes are commercially available for water treatment, 52 including microfiltration (MF), ultrafiltration (UF), nanofiltration (NF), and reverse osmosis 53 (RO) [4-6]. Recently, membrane distillation (MD) is introduced as an emerging technique that combines thermal and membrane separation [7-19]. Membrane distillation (MD) relies on a partial vapour pressure gradient generally caused by a temperature difference across the membrane [20,21]. Although MD was suggested decades ago, it is still in the developmental 
stages. One of the major reasons behind its late commercialization is the low recovery rate, severe temperature polarization, and, to a lesser extent, fouling of the membrane, especially when treating concentrated feed solutions [22, 23]. A range of cleaning techniques was used to control membrane fouling, including physical [24] and chemical $[25,26]$ cleanings. The advantages of these techniques include removing fouling materials from the membrane surface and increasing water flux by reducing concentration polarization. On the other hand, disadvantages are mainly i) reduced membrane lifetime [16, 27], ii) generation of contaminated wastewater [27], and iii) changes in membrane hydrophobicity and surface morphology [28, 29].

Recently, ultrasound (US) was proposed among other innovative cleaning techniques for water treatment processes, such as $\mathrm{CO}_{2}$ nucleation, which was tested for ultrafiltration [30] and reverse osmosis (RO) [31]. In water treatment context, US can be defined as the application of sound waves in frequency range higher than the human hearing limits. The detailed definition of terminologies used in ultrasound field and the parameters affecting its throughput will be discussed in the following section. US was integrated successfully with pressure-driven membrane separation [32-36] and emerging technology such as MD [37-42] to remove foulants from the membrane surface. The US-assisted membrane processes can significantly improve membrane performance. For example, water flux increase of up to $600 \%$ can be achieved with US help [5, 7]. In addition, US technology was applicable for fouling mitigation for various feed solutions such as surface water [4], milk solution [5], soybean [7] and oil wastewater [12].

77 The advantages of this cleaning technique are no chemical usage [43], no system shutdown and no need for membrane removal from the system for ex situ cleaning so that possible membrane contact with the air is minimized. Ultrasound removes deposited particles from the membrane surface as a result of it shaking. As a result, permeate flux through the membrane is increased.

81 Ultrasound can also increase a membrane's operation time by reducing the occurrence of 
82 fouling events. Several concerns are associated with applying US for mitigating membrane

83 fouling, such as high energy requirements [44], adverse effects on membrane integrity, and the selection of best system configuration that suits large-scale applications [45]. On the other hand, the advantages of US application for fouling mitigation are immense. They include reduced or no chemical usage [46], no system shutdown [39, 40], minimal effects on the environment and human health [39, 40, 47, 48] and high potential of scaling and biofouling removal $[49,50]$.

There are several studies that presented reviews on the application of ultrasound for improving membrane filtration technologies [35, 36, 51-54]. While these studies offer a comprehensive analysis of the commonly studied parameters in ultrasound-assisted membrane system such as power, frequency, medium pressure and temperature, membrane materials and flow conditions, this work discusses further the effect of other system parameters such as ultrasonic waveform, techniques for producing ultrasonic waves (piezo-electric and magneto-strictive) and system configuration on the overall performance of the system. In addition, most of these studies focused on the cleaning effects of ultrasound particularly at cavitational level, whereas this work addresses also the of effect ultrasound on flux enhancement with special attention paid to the potency of non-cavitational ultrasound effects. The other unique future of the current work is the attempt to establish connection between ultrasound energy output and the required energy to achieve the desirable change in the membrane separation process (flux enhancement and fouling removal). This could motivate further research to utilize advanced computational tools to fine tune energy usage in ultrasound-assisted membrane technology, which is the main challenge for scaling-up the process. This paper provides concise discussion for the impact of

104 ultrasound effects on fouling deposition onto membrane surface and mass and heat transfer 105 phenomena in membrane separation processes. The effect of US technology on the 106 performance of different membrane processes is also reviewed presenting up-to-date literature 
data and recent development in systems configurations. Recommendations and future research

108 directions are also proposed based on literature research findings and authors own views of the 109 process.

\section{2. Ultrasound effects on membrane processes}

111 Prior to reviewing and analysing the reported applications of ultrasound technology with

112 membrane filtration it is essential to briefly discuss the fundamentals of ultrasound technology.

113 Ultrasound is a term commonly used to refer to sound waves with frequency higher than the

114 human hearing limits $\geq 16 \mathrm{kHz}$ [45]. The introduction of ultrasound waves to liquid medium

115 such as water generates negative (rarefication phase) and positive (compression phase) pressure

116 swings. When the ultrasonic amplitude pressure surpasses the tensile strength of liquid, bubbles

117 are formed [51]. These bubbles grow in the negative cycle of pressure and collapse during the

118 positive swing of the pressure. Bubbles produced during ultrasonic waves propagation are

119 generally categorised into transient bubbles that collapse violently and stable bubbles that

120 collapse gently [55]. In addition to the bubbles generated in the liquid phase, bubbles can also

121 be produced at the liquid-solid interface. The process of bubbles generation in liquid phase is

122 termed as homogenous cavitation, while bubbles generated in the liquid-solid interface is

123 known as heterogeneous cavitation [56]. Pre-existing bubbles in the liquid can also grow to

124 transient or stable bubbles depending on their sizes. The movement of ultrasound waves in the

125 liquid medium and bubbles oscillation and collapse generate a range of physical effects that

126 have been harnessed to enhance membrane technology performance. The impact of these

127 effects on the dynamics of membrane separation processes on one hand and their influence by

128 ultrasound operation parameters on the other hand will be discussed succinctly in later parts of

129 this section.

130 To maximise the benefits of ultrasound application with membrane-based technologies, it is

131 imperative to understand the enhancement mechanisms of ultrasound and how the operating 
132 parameters and process environment influence these mechanisms. Ultrasound impacts

133 membrane filtration through three pathways: detaching deposited foulants and driving particles

134 and molecules away from the membrane interface (i.e. reducing concentration polarization)

135 (cleaning effects), improving water transport across the membrane (mass transfer effects) and

136 boosting heat transfer of water for thermally-driven membrane processes [45].

137 The propagation of ultrasound waves results in several effects such as acoustic streaming,

138 microstreaming, micro-streamers, micro-jets and shock waves generated from transient

139 bubbles collapse [45]. The definition and detailed explanation of these phenomena are well

140 documented in the literature $[24,49,57,58]$. The occurrence and intensity of ultrasonic effects

141 depend on factors such as power, frequency, environmental conditions of the treatment (i.e.

142 pressure and temperature), nature of the irradiated water, operation mode, mechanical

143 vibration, and excitation wave shapes.

144 The ultrasound effects can be classified into cavitational and non-cavitational, depending

145 mainly on power and frequency, as demonstrated in Figure 1. Apart from acoustic streaming,

146 Figure 1 shows that other events can only occur if the applied acoustic pressure exceeds a

147 threshold pressure and frequency is lower than $\mathrm{MHz}$ range. Blake pressure threshold is

148 commonly applied to estimate the minimum ultrasonic power required for generating cavitation

149 in given conditions [59]. Ultrasound power higher than cavitation threshold can overcome the

150 cohesive forces of the medium and generate bubbles. The higher the applied power, the more

151 violent ultrasonic effects are expected to occur. For ultrasound-assisted membrane technology,

152 high power may damage the membrane. Hence, if more energy required to improve fouling

153 detachment or fluid dynamics in the adjacent area to the membrane, longer treatment time

154 applied.

155 Contrary to the power, increasing frequency reduces the intensity of acoustic events except for

156 acoustic streaming. A study conducted by Costalongaet al. [60] demonstrated that acoustic 
streaming velocity increases with frequency. The fluid pattern changes with frequency, and rotational flow diminishes as the frequency increases. A linear motion occurs, especially in the middle of the irradiating surface, as shown in Figure 1. When it comes to the cleaning effects

160 of ultrasound, the linear motion can be problematic as it may push the fouling particles deeper 161 into the membrane pores instead of pushing them away, as observed in the circular motion.

162

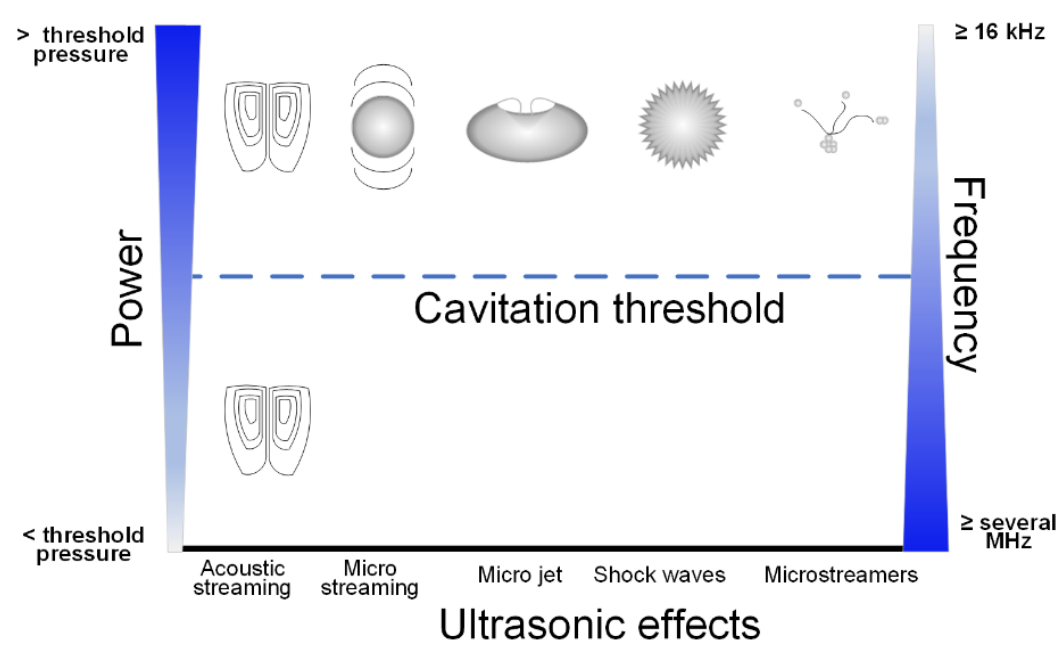

Figure 1: a) Influence of power and frequency on ultrasound effects.

163

164 Temperature and pressure of the medium can influence ultrasonic events through their effects on medium properties and bubble dynamics. For instance, higher power is required for the ultrasonic wave to propagate and generate bubbles in a pressurized medium. The opposite is 167 also true in a medium under high temperature [61]. Increasing the temperature reduces the

168 medium viscosity and surface tension facilitating the generation of cavitating bubbles.

169 However, such action can also generate bubbles with less violent collapse [62].

170 Fluid properties may also impact the nature of its interaction with ultrasonic waves. For 171 example, the type of dissolved gas affects the thermal product of the collapse. Gases with a 172 high adiabatic ratio result in bubble collapse with high temperature [63]. Heavy gases can 173 produce high collapse temperatures, but they have low thermal conductivity and convey the 174 heat from collapse sites to the bulk slower than light gases [63]. The fluid content of dissolved 
175 and suspended solids can also influence ultrasound effects. It was found that both the number

176 of bubbles and their size decreases with an increasing salt concentration in water [64].

177 The operation details of ultrasonic devices can also play an important role in controlling 178 ultrasonic effects. The effect of such details on ultrasound performance in assisting membrane 179 filtration is scarcely investigated in the literature. These details include the operation mode 180 (continuous or pulsed), vibration generation techniques (piezoelectric or magnetostrictive) and 181 the excitation wave (sinusoidal, square, triangle etc.). Applying pulsed mode was more 182 effective in utilizing energy and producing more cavitational effects [65]. In terms of the 183 operation mode on non-cavitational effects (i.e. acoustic streaming), it was reported that 184 applying this mode reduces the acoustic streaming velocity[66]. Therefore, depending on how vigorous the acoustic streaming needs to achieve treatment performance, such as removing a fouling layer or improving mass/heat transfer phenomena, one can decide whether to apply continuous or pulsed mode. Some studies found continuous mode more beneficial for improving membrane filtration flux [67], while others found that pulsed mode is more effective

189 [68]. The techniques used to generate mechanical vibrations in the transducer impact both the 190 efficiency and durability of ultrasonic devices. Magneto-strictive transducers are reported to be more resistant to mechanical impact, more tolerant to high temperatures and have longer working life compared to piezoelectric transducers [69]. The latter type of transducers is commonly used in membrane filtration studies due to its availability as an off-the-shelf product

194 in the market. This may be one reason that makes the ultrasound technique perceived to be 195 costly. Kyllönen et al., [35] concluded that the main reason that hinders the commercialisation of ultrasonic-assisted membrane technology is the absence of active efforts for developing transducers that cater for this application. The effect of the excitation wave on the transducer's electrical output and the cavitational chemical yield (measured by $\mathrm{OH}^{*}$ and $\mathrm{H}_{2} \mathrm{O}_{2}$ production) was evaluated by Al-juboori et al. [69]. The results showed that among the tested waveforms, 
square wave resulted in the best transducer displacement and the highest concentration of $\mathrm{OH}^{*}$ and $\mathrm{H}_{2} \mathrm{O}_{2}$. A numerical study by another team Kerboua, and Hamdaoui [70], on bubble dynamics under different excitation waveform showed that a square wave produces the highest pressure and temperature inside the bubble compared to triangle and sinusoidal waves.

\subsection{Effects of ultrasound on fouling}

205 Applying the US for removing/preventing fouling layer formation requires an adequate understanding of the forces acting on the particle in a dynamic system. There are mainly four forces exerted on a particle at the membrane/water interface, as depicted in Figure 2. These forces are the lubrication force $\left(F_{L}\right)$, the adhesion/repulsion force $\left(F_{A / R}\right)$, the tangential drag force $\left(F_{T}\right)$ and the friction force $\left(F_{F}\right)[71,72]$. The roughness variation of the membrane surface

210 is represented by $\delta$ in Figure 2. For additional details regarding forces affecting a particle 211 deposition onto a membrane surface, readers are referred to existing literature [71, 72] and 212 references presented therein.

213 The impact of US on deposited particles is mainly governed by power intensity and the 214 effective distance from the membrane surface. From the force balance presented in Figure 2, it 215 can be inferred that the particle adhesion condition is satisfied when $F_{T}=F_{F}$ and $F_{A} \geq F_{L}$.

216 Hence, the forces generated by US effects need to tip the balance in favour of tangential force

217 and lubrication. For instance, the hydrodynamic force $\left(F_{s}\right)$ generated by the acoustic streaming 218 (eq. 1 [73]) or the shock wave energy $\left(E_{S W}\right)$ generated from bubble collapse (eq. 2 [74]) need 219 not only to exceed the friction force but to also move the particle away from the membrane.

$$
\begin{gathered}
F_{S}=\frac{P_{U S}}{c} e^{-2 \alpha x} \\
E_{S W}=\int \frac{\Delta P^{2}}{(\rho c)^{2}} d V
\end{gathered}
$$


where $P_{U S}$ is the US power $(\mathrm{W}), c$ is the speed of sound $(\mathrm{m} / \mathrm{s}), \alpha$ is the attenuation coefficient of the acoustic pressure in water $\left(\mathrm{m}^{-1}\right), x$ is the distance between the irradiating surface and the membrane (m), $\Delta P$ is the pressure difference across bubble wall, and $V$ is the cavitating bubble

224 volume $\left(\mathrm{m}^{3}\right)$.

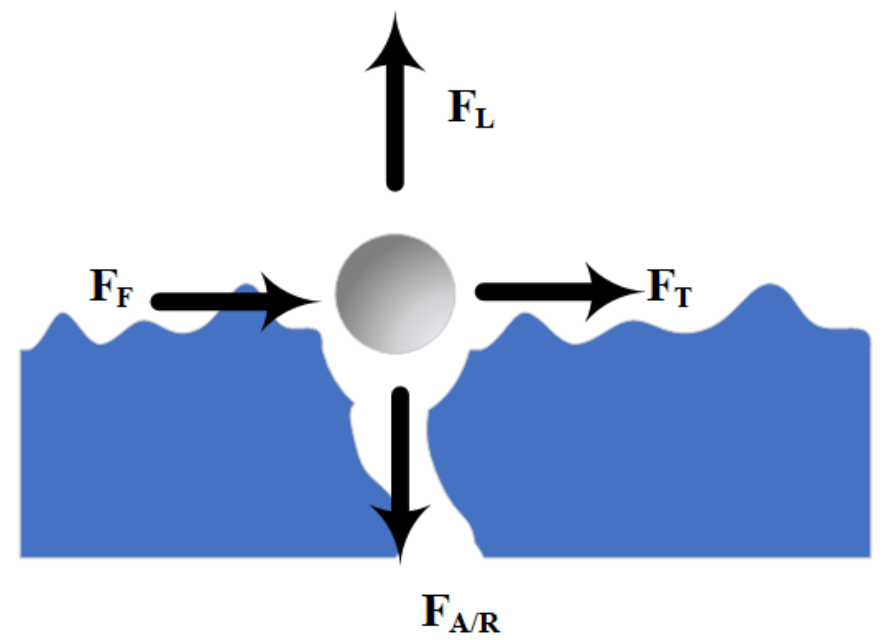

Figure 2: Forces acting on a particle being deposited onto a membrane pore.

As for the effective range of ultrasonic events, an illustrative representation is provided in Figure $3[24,57,75]$. It is clear that except for acoustic streaming, other ultrasonic effects need to occur close to the membrane-water interface to remove particles from the membrane surface. Several studies [68-70] reported these effects are more intense than acoustic streaming, raising concern of possible membrane damage. Strong forces such as those generated by the cavitational effects are only needed when the fouling layer is already established. This also depends on the fouling type: cake layer or pore blocking. The US was found to be less effective in removing pore-blocking fouling as opposed to the cake layer fouling [76]. Given the fact

234 that the US is not effective in removing all forms of developed fouling on the membrane and the potential damage cavitation effects may cause, one can deduce that the most efficient way to apply the US for alleviating the fouling problem is by utilizing low power non-cavitational effects to prevent/reduce fouling formation at early stages of filtration. 


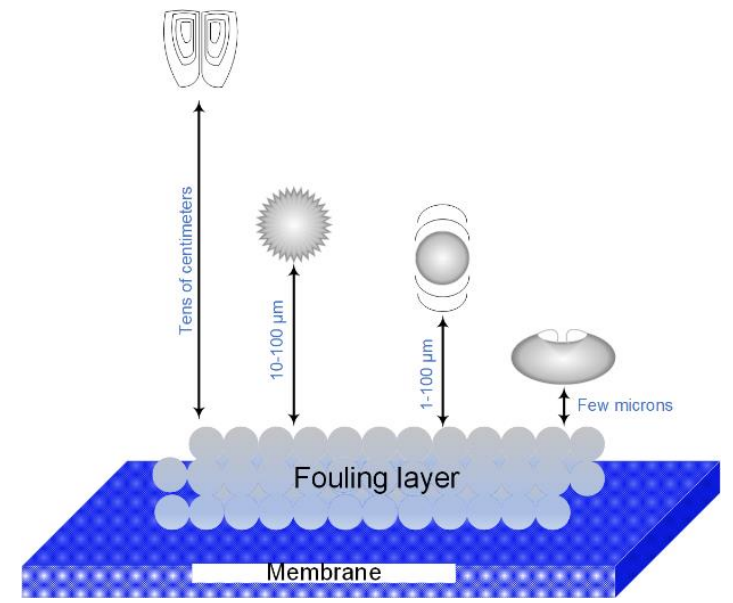

Figure 3: Active ultrasonic effects' distance.

\subsection{Mass and heat transfer enhancement}

241 The US can affect mass transfer through its influence on flow nature by generating turbulence

242 in the membrane's vicinity. However, the direction of turbulences needs to be in the same

243 direction as the flow; otherwise, it may slow down the water near the membrane surface,

244 promoting fouling. The velocity of the turbulences can be estimated using dedicated equations

245 such as the maximum acoustic streaming velocity formula (eq. 3) [77], where $v$ is the vibrating

246 velocity $(\mathrm{m} / \mathrm{s}), k$ is the wavenumber, $\delta$ is the boundary layer thickness $(\mathrm{m}), y$ is the distance to

247 the membrane surface (m), and $a$ is the transducer radius (m). The direction could also be

248 identified based on the mounting of the emitting surface onto the membrane module. Species

249 diffusion coefficient being a function of pressure and temperature [78], US can affect diffusion

250 through pressure and temperature increase that results from US effects.

$$
u_{a s}=\frac{3 v^{2} \delta a^{6} k^{3}}{8 c x^{4}}\left\{1-\frac{y}{\delta}-\left(1-\frac{y}{\delta}\right)^{3}\right\}
$$

252 The effect of the US on heat transfer is mainly related to its impact on the convective heat transfer coefficient on the feed side. The US increases the convective heat transfer coefficient by a component $\left(h_{a s}, \mathrm{~W} / \mathrm{k} \cdot \mathrm{m}^{2}\right)$ presented in eq. 4 , where $C_{p}$ is the specific heat of water 
$255(\mathrm{~kJ} / \mathrm{kg} \cdot \mathrm{K})$. Knowing the velocity of the acoustic streaming and the feed water properties, one can estimate the extent of enhancement expected with a chosen set of operating conditions.

$$
h_{a s}=\rho v_{a s} C_{p}
$$

\section{Integration of US with pressure-driven membrane technology}

There are two types of US connections in the membrane module, i.e. in-situ (internal) and exsitu (external) [39]. The advantage of the in-situ connection is that it requires low US power to remove the fouling layer from the membrane surface as the transducers can be close to the not all, on using US-assisted pressure-driven membrane technologies adopted the ex-situ configuration to avoid membrane damage [79]. However, as stated earlier, this requires highenergy consumption to convey the effects to the membrane surface. The purpose of applying to the US could also vary. Some studies applied ultrasound as an offline cleaning technique, while others applied it as an online cleaning technique that could simultaneously enhance water flux. The following sections discuss the coupling of US with various pressure-driven membrane processes.

\subsection{MF-US.}

Microfiltration (MF) is considered one of the most common membrane technologies used for water and wastewater treatment. The MF technology showed great potential in treating various wastewaters. However, membrane fouling is a critical issue in MF, which significantly affects process performance. Among techniques used for cleaning MF, US technology has captured considerable attention, and the majority of ultrasound applications for membranes cleaning was trailed using MF setups. 
278 Table 1 shows a summary of the studies conducted using the US with pressure-driven 279 membrane technologies. It should be noted that the authors tried to include all relevant 280 information available in the reported studies with the focus on US effects alone membrane 281 performance. Some information such as the thickness of the tested membranes before and after 282 filtration and cleaning processes are rarely reported in the literature. Hence, they have not been 283 covered in this review.

284 A range of synergistic techniques has been reported to improve membrane throughput when combined with the US. Sanderson et al. [80] found that combining forward washing with ultrasound for offline cleaning of MF membrane fouled with paper mill wastewater improved

287 permeate flux by $750 \%$ compared to only $300 \%$ with ultrasound alone. Another study reported that adding ethylenediaminetetraacetic acid (EDTA) to feed solution while applying ultrasound on the fouled membrane with milk solution enhanced the flux further. A mixed frequency of 28, 45 and $100 \mathrm{kHz}$ was the least affected by EDTA addition than individual frequencies [81]. There is other possible synergestic processes that incorbrate ultrasound with membrane technology and adsorption in a hybrid system as a combination of filtration and adsorption has

293 proven to be effective for treating wastewater [82]. As an example for such hybrid system is the combined UF, US and activated carbon processes tested by Mona et al. [83] for removing industerial dyes. The ourcome of these studies is summaries in Table 1. Another synergy that can benefit from ultrasound application is the hybrid electro-chemical and adsorption system

297 such as the one reported by Kadhum et al. [84] if combined with membrane technolgy assited 298 by electro-chemical techniques [85]. Although such combination has not been reported in the 299 literature, one can postulate the potential benefit of ultrasound. For instance, ultrasound can 300 improve the adsorption capacity of adsorbents [83] and allivate the impact conencertation 301 polarization on membrane and electrodes [86]. However, ultrasound physical and chemical 302 effects can lead to the destruction of electrodes just as it is the case with posible membrane 
303 surface deterioration [87]. The other possible risk with such combinesd systems is that if the

304 adsorbents are immoblised on membrane surface, ultrasound effects could detach them

305 rendering the membrane structure weak and more prone to serious damage.

306 The compiled information in Table 1 is useful to gain an in-depth understanding of the effects

307 of membrane and ultrasound operating conditions on the overall performance of the US-

308 assisted membrane process. There are three ways for pressure-driven membrane processes

309 through which the US is applied: online flux enhancement, pretreatment and offline cleaning.

310 Online flux enhancement appears to be the most effective form of US application. Examples

311 of common US-membrane design systems are illustrated in Figure 4. In addition to the 3

312 designs mentioned above, there are self-cleaning US-vibrated piezoceramic membranes that

313 have recently been developed and found to increase the flux by about $30 \%$ when the vibration

314 is in operation [88]. It appears that increasing the input US energy either through increasing

315 the applied power or the irradiation time affects the permeate flux negatively. This is likely to

316 occur due to high power density, resulting in the breakdown of particles leading to severe pore-

317 blocking fouling. For the case of MF, two studies [67, 89] showed the adverse effect of

318 ultrasonic energy on membrane flux used a high power density of $200 \mathrm{~W} / 1$ - $300 \mathrm{~W} / 1$. Similarly,

319 the increasing frequency seems to result in lower permeate flux enhancement. This has been

320 attributed to the negative effect of frequency on cavitation threshold and bubble growth [90].

321 Evaluating the effect of frequency of flux with non-cavitational effect has not been addressed

322 in the literature. In this case, a higher frequency may be useful as more wave cycles are

323 generated. A mix of low and high frequency was more powerful than the low frequency alone

324 [81]. It appears that the pressure has an inverse correlation with permeate flux enhancement.

325 The latter is expected since pressure increase raises the resistance against the propagation of

326 the sound wave. 
327 Regarding the effect of membrane materials on the efficiency of US cleaning, a study 328 conducted by Wang et al. [91] tested polyethersulfone (PES), mixed ester of cellulose nitrate 329 with cellulose acetate, PVDF and nylon six and found that the latter exhibits the highest 330 permeate flux improvement. For more details on membrane materials effect on US 331 performance, readers are referred to the study by [51]. However, this study pinpointed that it 332 was hard to conclude from the literature regarding the effect of membrane materials on US effectiveness.

334 Some researchers have investigated other parameters, such as the distance between the emitting 335 surface of the ultrasound and the membrane surface. Mirzaie and Mohammadi [67] observed a 336 drop in flux enhancement of MF-US from $228 \%$ to $145 \%$ when the distance between the US 337 horn and the membrane surface was increased from $2.6 \mathrm{~cm}$ to $4.4 \mathrm{~cm}$. However, increasing the distance between the ultrasound source and membrane surface does not always have a negative impact on flux enhancement. Thus, [92] showed that increasing the distance between ultrasonic

340 transducer and membrane from $4 \mathrm{~cm}$ to $8 \mathrm{~cm}$ increased the flux from $5.8 \times 10^{-5} \mathrm{~m}^{3} / \mathrm{m}^{2}$. $\mathrm{s}$ to 7.5

$341 \times 10^{-5} \mathrm{~m}^{3} / \mathrm{m}^{2} \mathrm{~s}$. However, when the distance was further raised to $12 \mathrm{~cm}$, permeate flux declined 342 to $7.1 \times 10^{-5} \mathrm{~m}^{3} / \mathrm{m}^{2} \cdot \mathrm{s}$. The observed effect was attributed to the uniformity and intensity of the 343 ultrasonic field governed by the applied power, the reactor design and the nature of the 344 irradiated fluid. As stated earlier, the content of the water being irradiated could influence 345 ultrasound performance. It was reported that increasing particles concentration in water from $346 \quad 0.1 \mathrm{~g} / \mathrm{L}$ to $1.8 \mathrm{~g} / \mathrm{L}$ resulted in a decrease in permeate recovery of US-assisted membrane 347 technology by 60\% [93]. 


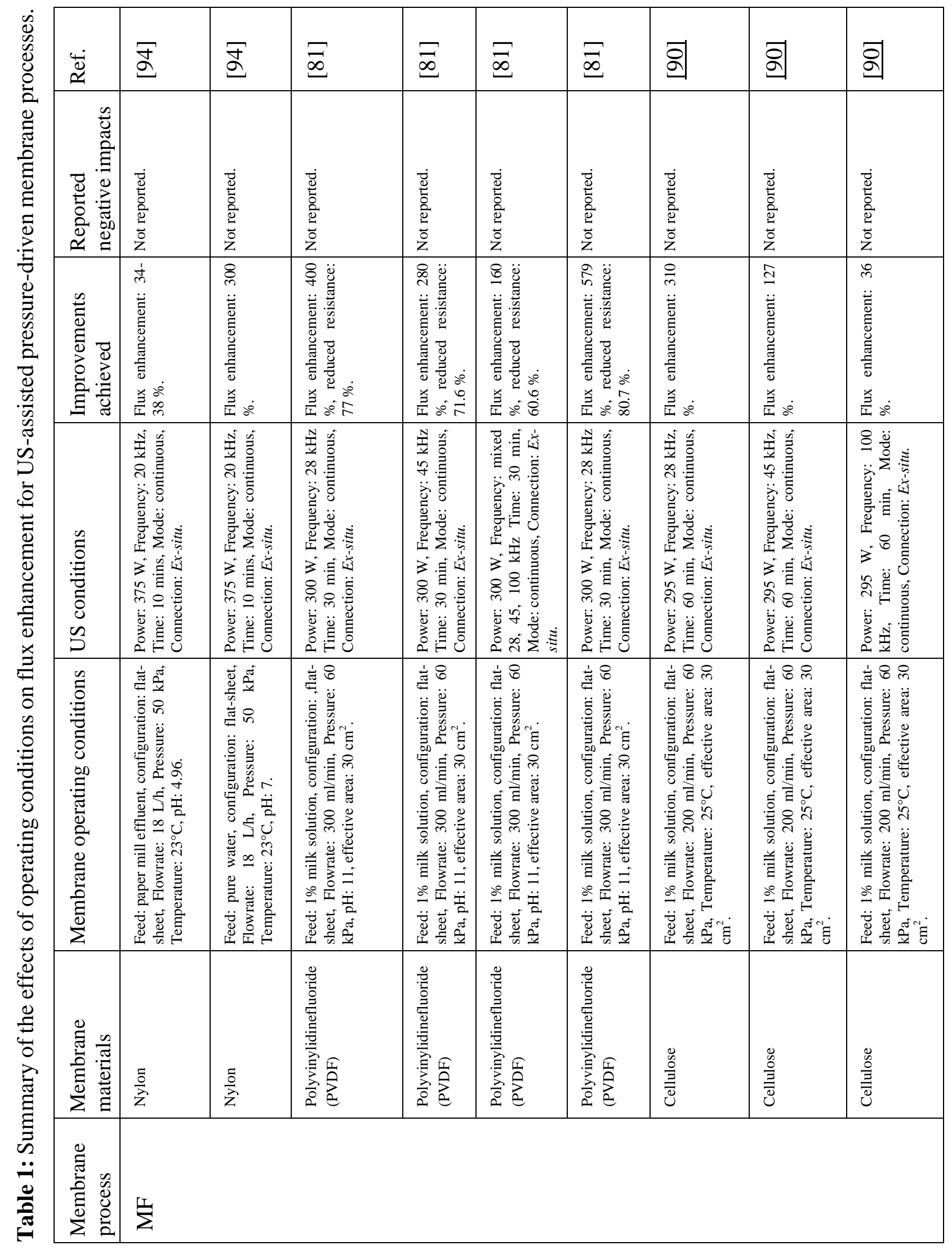




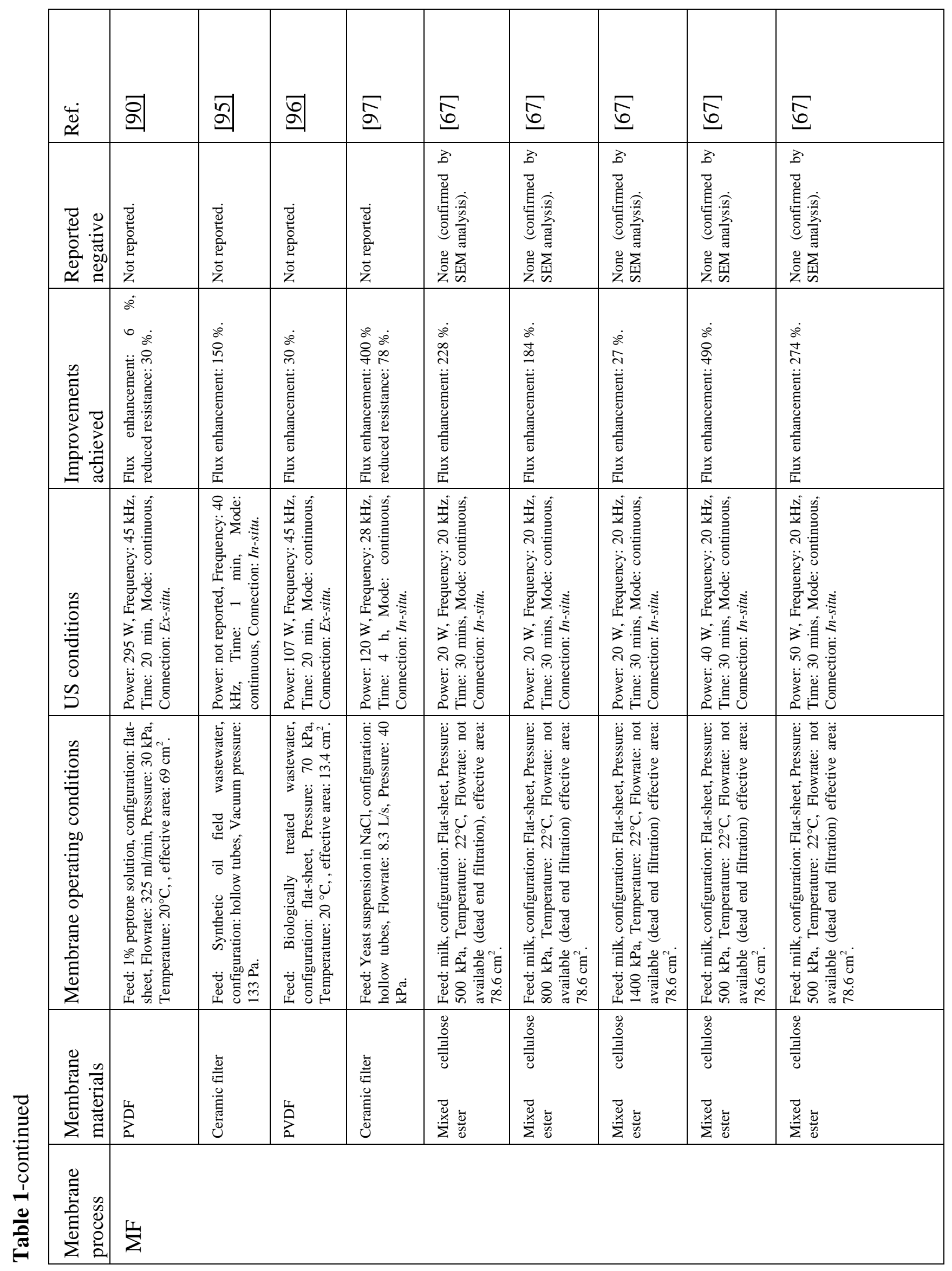




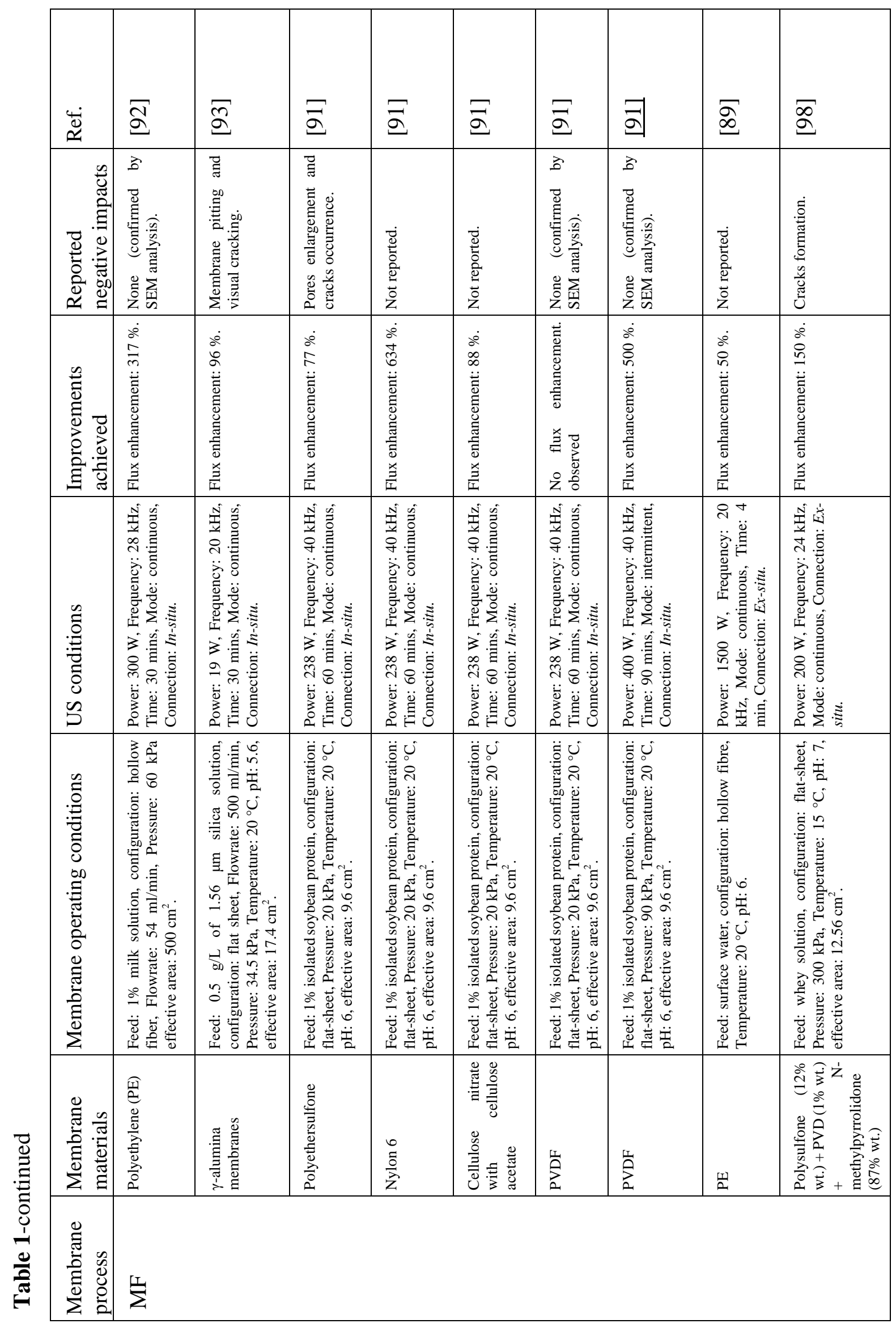




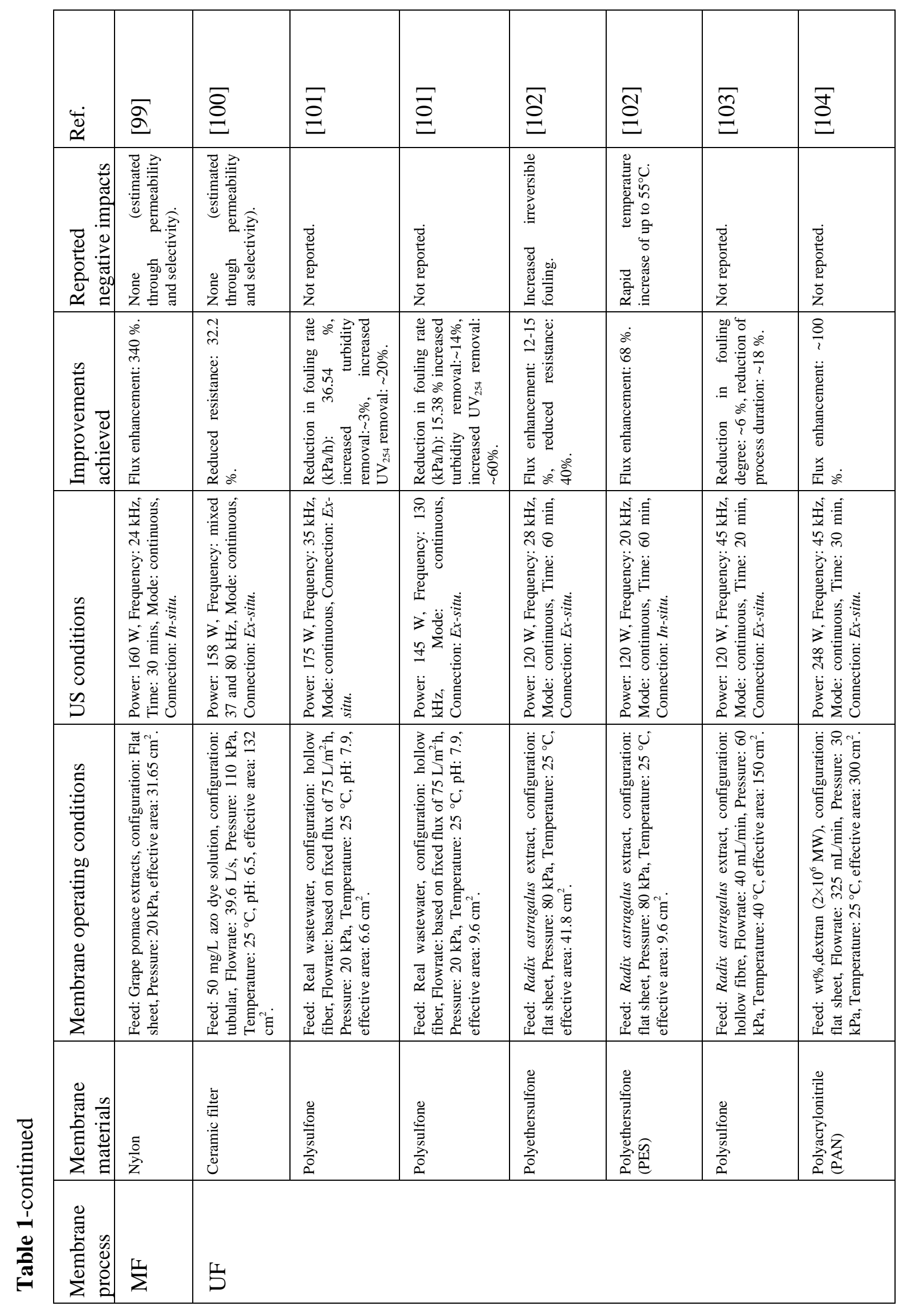




\begin{tabular}{|c|c|c|c|c|c|c|c|c|}
\hline 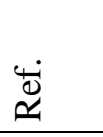 & $\sqrt{\varrho}$ & $\stackrel{8}{\circ}$ & $\widehat{\sigma}$ & $\underline{\sigma}$ & $\stackrel{\infty}{\varrho}$ & $\stackrel{8}{\varrho}$ & $\bar{\infty}$ & $\bar{\infty}$ \\
\hline 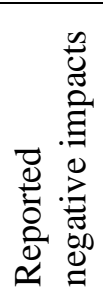 & 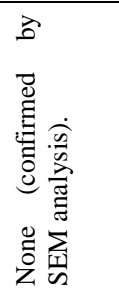 & 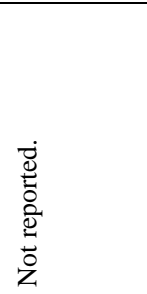 & 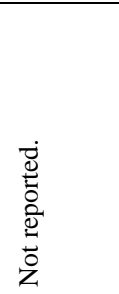 & 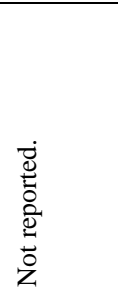 & 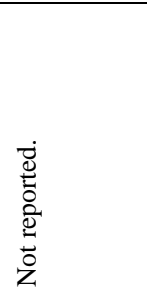 & 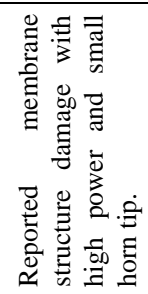 & 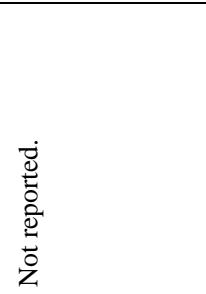 & 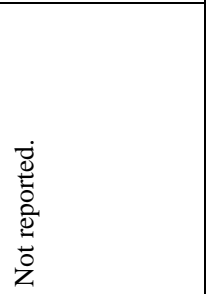 \\
\hline 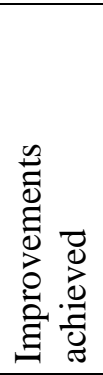 & 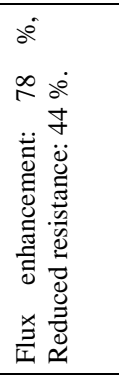 & 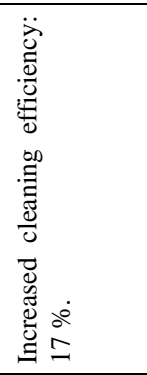 & 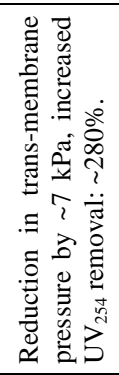 & 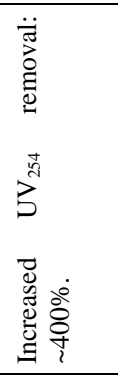 & 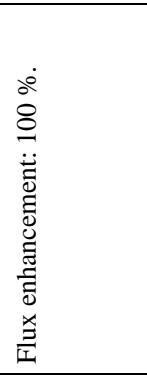 & 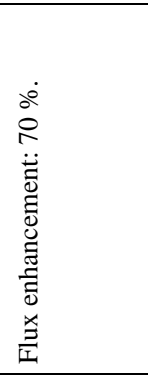 & 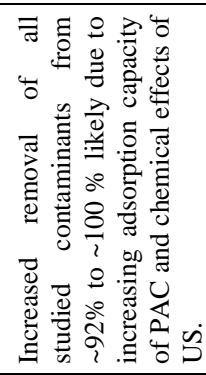 & 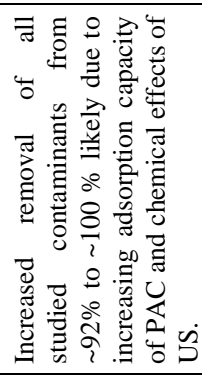 \\
\hline 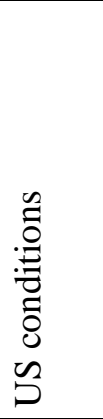 & 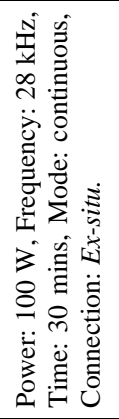 & 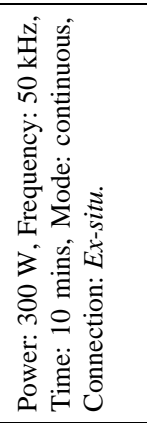 & 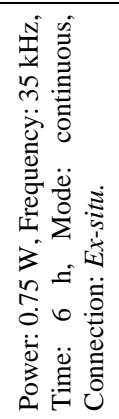 & 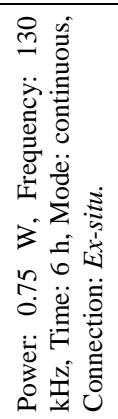 & 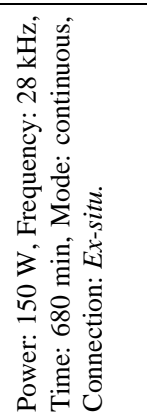 & 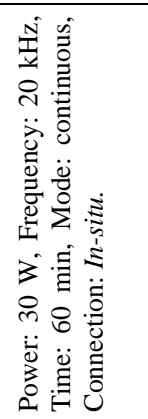 & 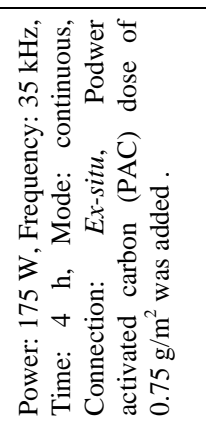 & 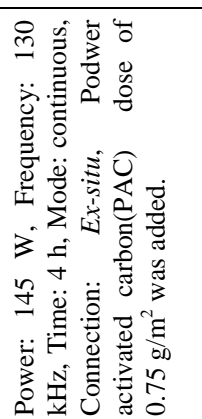 \\
\hline 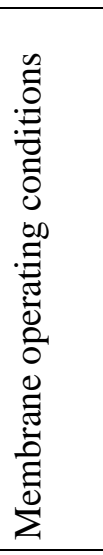 & 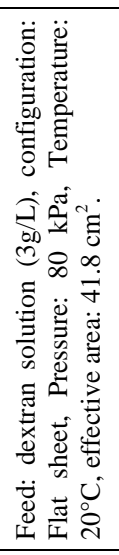 & 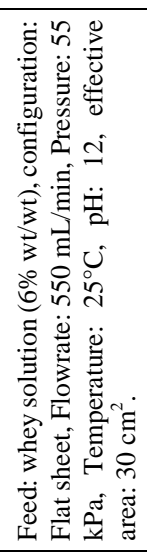 & 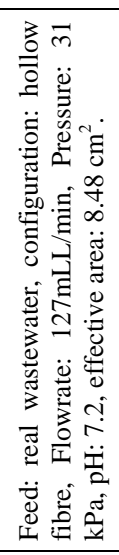 & 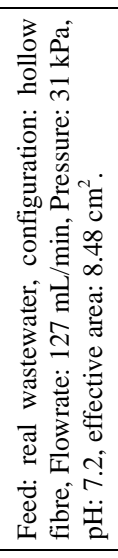 & 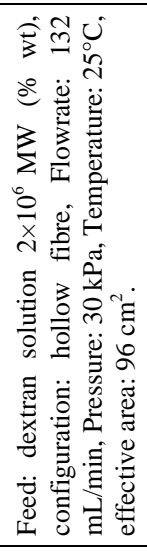 & 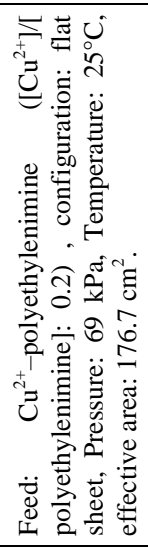 & 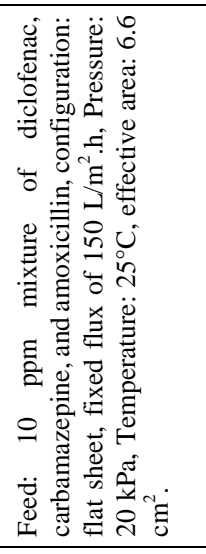 & 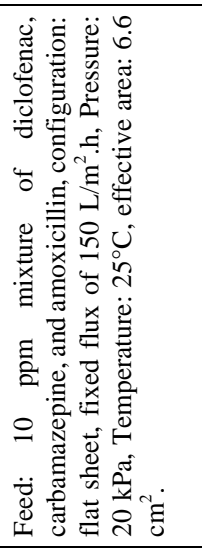 \\
\hline 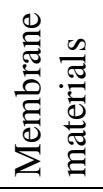 & 兄 & $\begin{array}{l}0 \\
\stackrel{0}{0} \\
\stackrel{0}{7} \\
\frac{0}{0} \\
0\end{array}$ & $\begin{array}{l}\stackrel{0}{0} \\
\stackrel{0}{\overline{7}} \\
\frac{0}{2} \\
\stackrel{0}{0}\end{array}$ & $\begin{array}{l}0 \\
\stackrel{0}{0} \\
\stackrel{0}{7} \\
\frac{0}{2} \\
\stackrel{0}{0}\end{array}$ & $\underset{\Omega}{Z}$ & 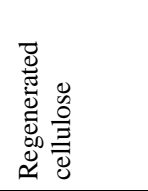 & $\begin{array}{l}0 \\
\stackrel{0}{0} \\
\frac{0}{7} \\
\frac{0}{2} \\
2\end{array}$ & $\begin{array}{l}\frac{0}{0} \\
\frac{0}{0} \\
\overline{0} \\
\frac{2}{0} \\
2\end{array}$ \\
\hline 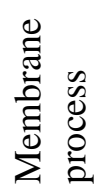 & 屿 & & & & & & & \\
\hline
\end{tabular}




\begin{tabular}{|c|c|c|c|c|c|c|c|}
\hline ๕ü & $\stackrel{\Xi}{\Xi}$ & $\Xi$ & $\bar{\Xi}$ & $\stackrel{\bar{m}}{\Xi}$ & $\bar{\Xi}$ & $\stackrel{\Xi}{\Xi}$ & $\underset{\Xi}{\Xi}$ \\
\hline 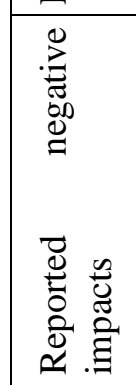 & 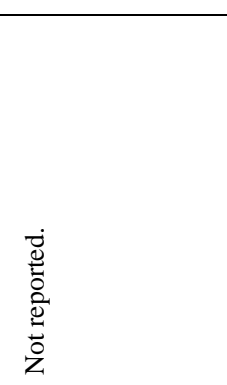 & 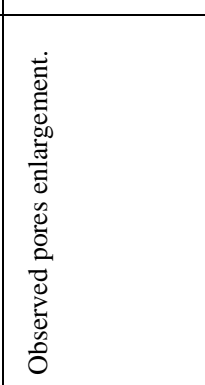 & 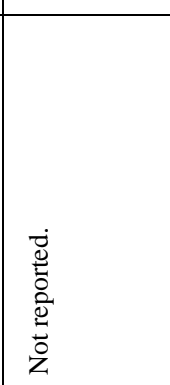 & 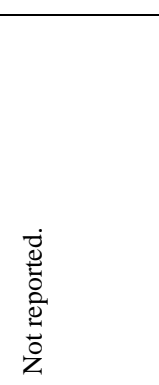 & 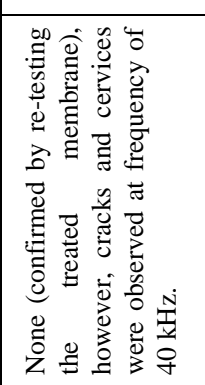 & 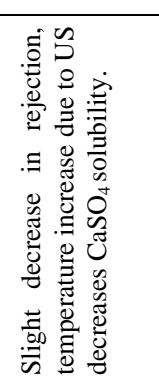 & 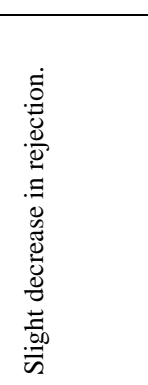 \\
\hline 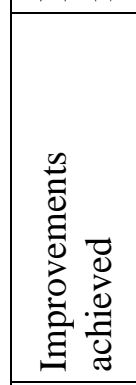 & 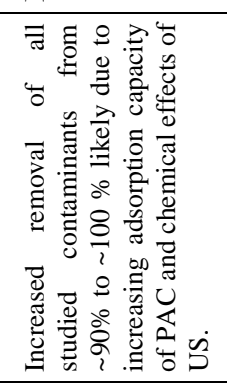 & 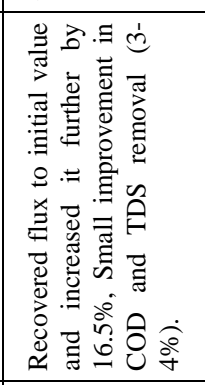 & 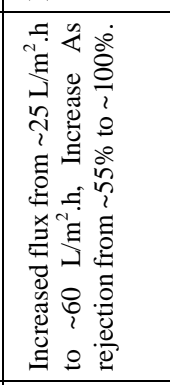 & 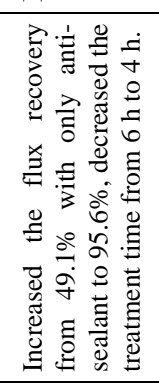 & 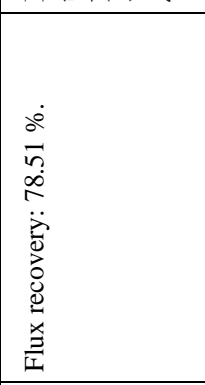 & 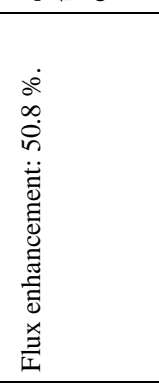 & 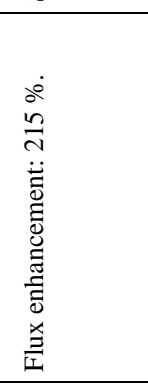 \\
\hline 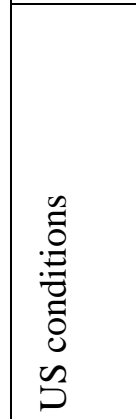 & 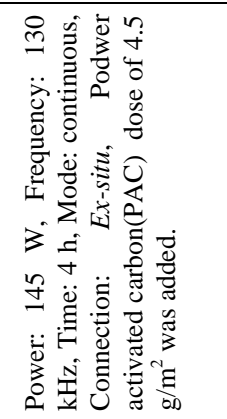 & 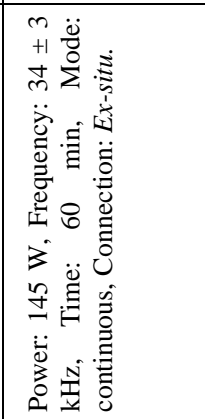 & 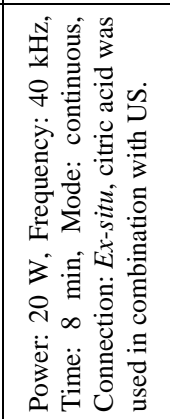 & 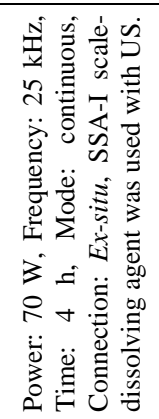 & 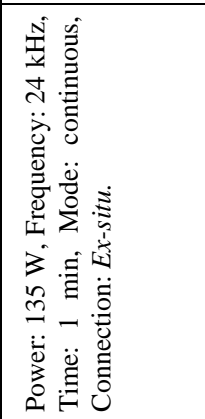 & 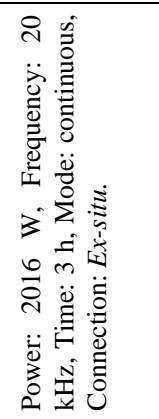 & 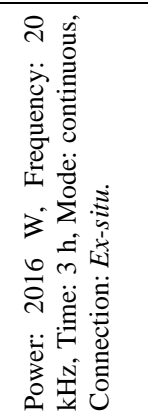 \\
\hline 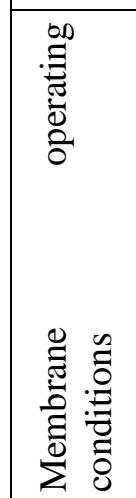 & 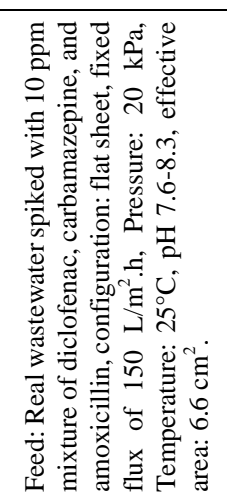 & 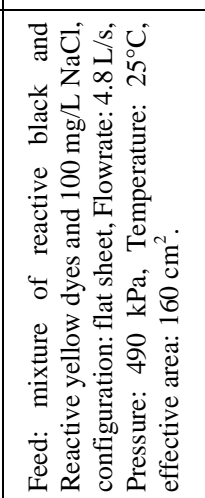 & 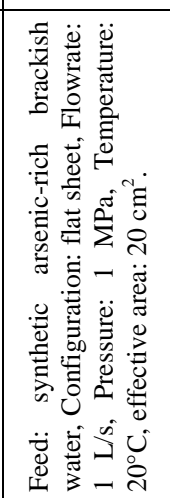 & 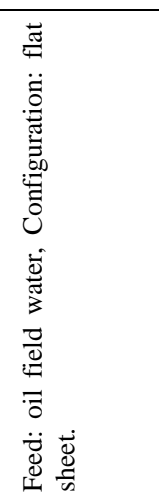 & 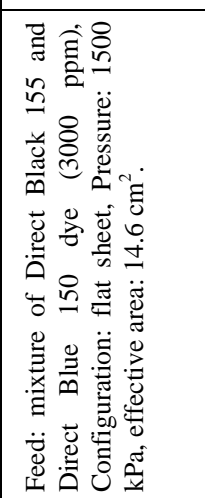 & 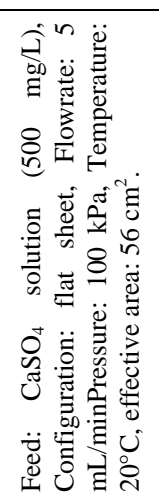 & 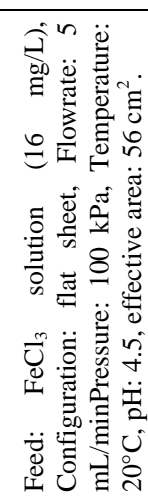 \\
\hline 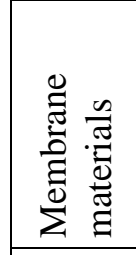 & 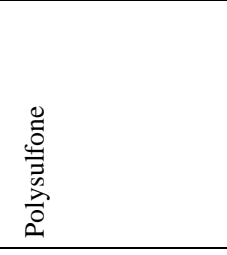 & 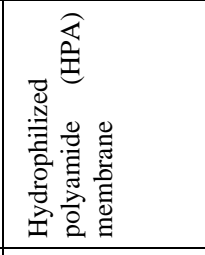 & 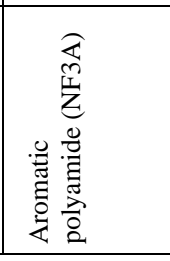 & 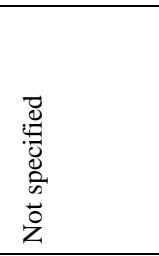 & 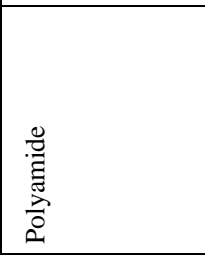 & 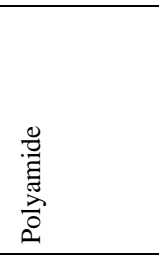 & 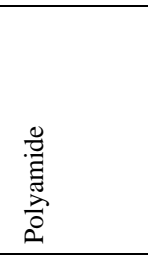 \\
\hline 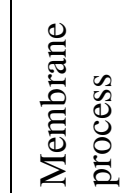 & Is & $\frac{1}{z}$ & & & & \& & \\
\hline
\end{tabular}




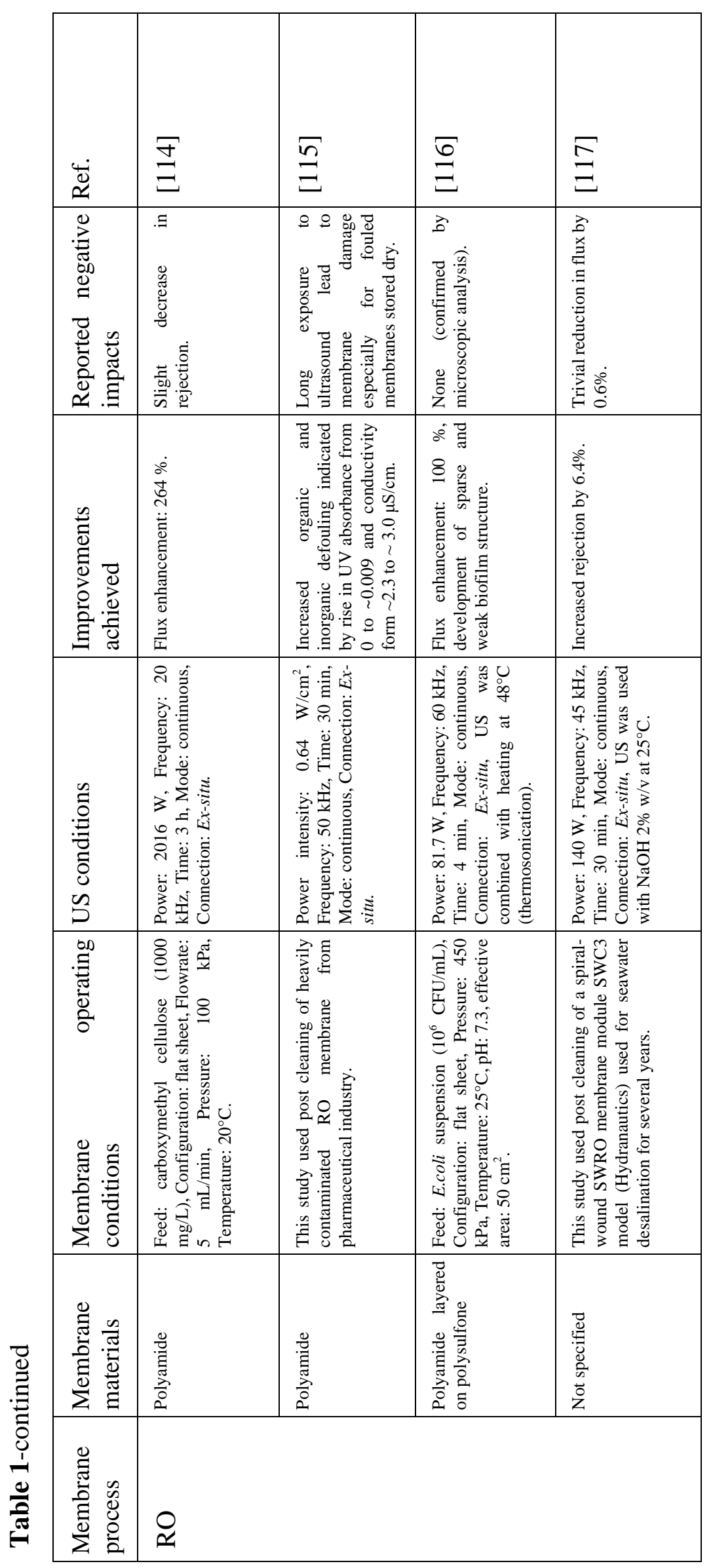




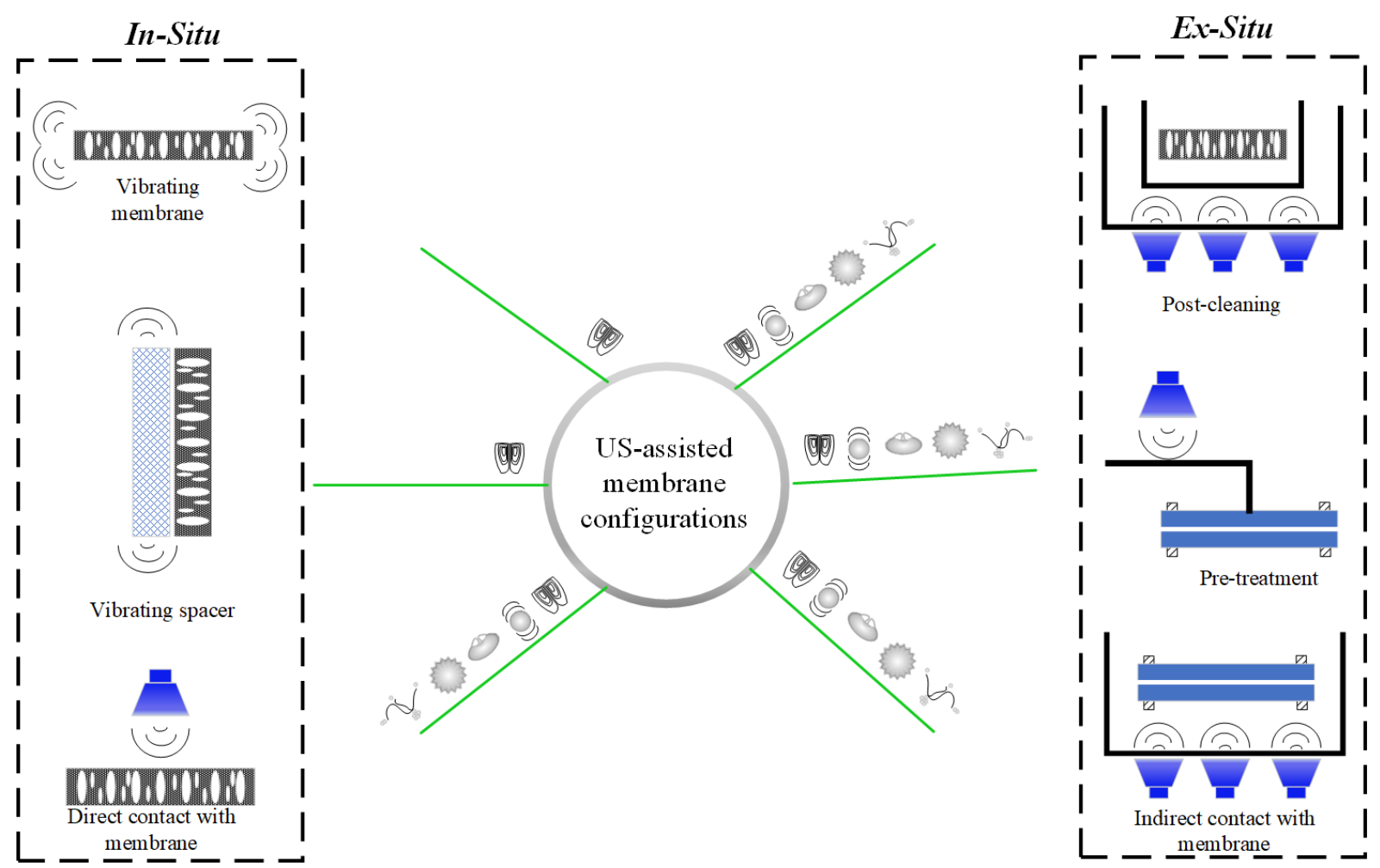

Figure 4: US-assisted membrane configurations with their effective mechanisms for membrane performance improvement.

\section{2. $U F-U S$}

360 Ultrafiltration (UF) is a promising separation process that covers a wide range of industrial processes, including concentration, fractionation, water treatment and macromolecular species

362 elimination or macro-solutes elimination from various industrial effluents [118, 119].

363 Membrane fouling is a serious issue with UF membranes, causing a decrease in permeate flux

364 and increasing process and maintenance costs. Different chemical and physical methods have

365 been used for UF membrane cleaning [100, 120]. Physical cleaning might change the membrane's hydrodynamics, while chemical cleaning can be expensive [121]. US technology

367 is considered for cleaning the UF membrane using a bath configuration, as illustrated in Figure

3685.

369 Table 1 shows a summary of the studies conducted using the US combined with pressure-

370 driven membrane technologies. Various sonication modes have been used in US-assisted UF,

371 such as continuous, pulsed, sweeping, and degassing, to improve process performance. 
372 Shahraki et al. [68] studied the effect of different sonication modes (continuous, pulsed, 373 sweeping, and degassing) on permeate flux and fouling of flat sheet UF polyethersulfone 374 membrane. The optimum UF process was achieved at $37 \mathrm{kHz}$ using a pulsed mode, which 375 corresponds to a percentage of fouling and effect of sonication factor of $10.53 \%$ and $187.4 \%$, 376 respectively. The US pulsed mode is more energy-efficient than the continuous mode. This is 377 critical for implementation because one of the main US disadvantages is the energy cost. The 378 US energy cost is high and would be only useful for a laboratory test [109]. Another reason for this optimum filtration process is the US's low frequency, which could increase the removal of 380 the fouling layer from the membrane surface. The low US frequency results in 1) localized turbulence and stronger vibration $[101,122]$ and 2) lower concentration polarization and the cake layer resistance $[90,102,105,123]$.

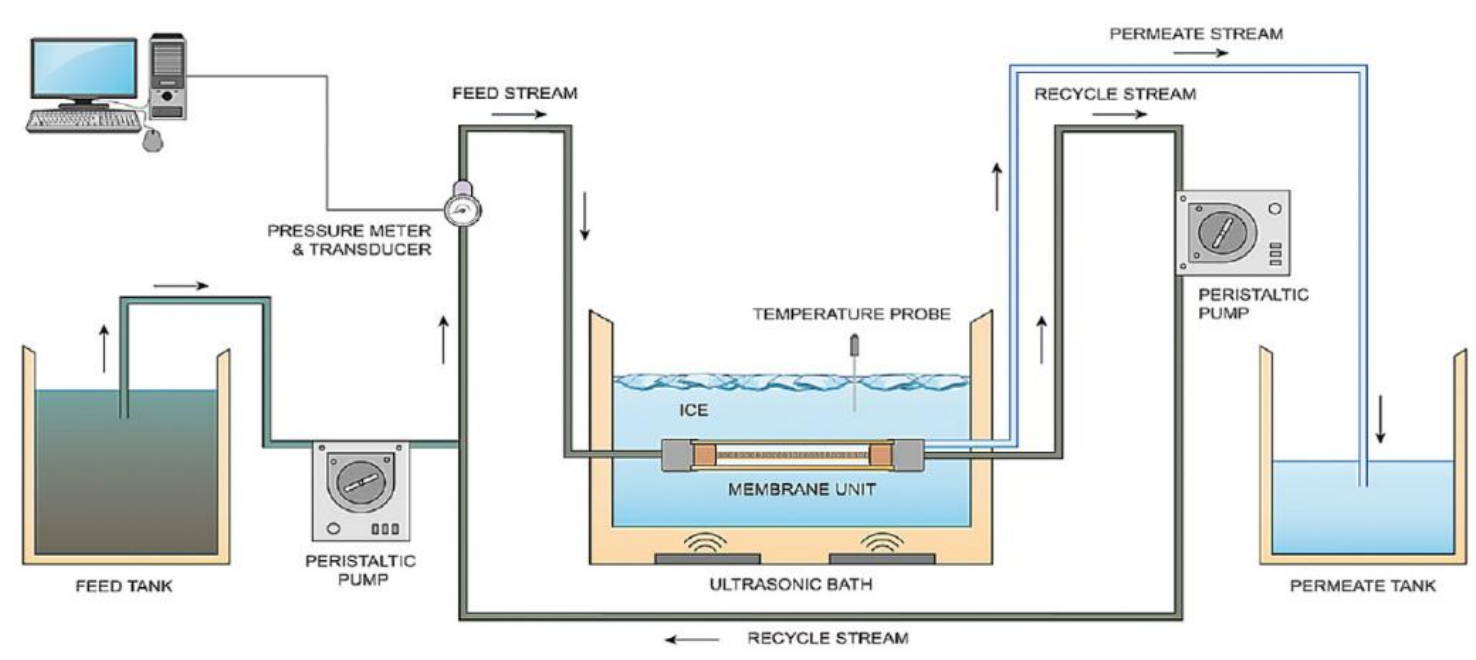

Figure 5: Schematic of UF-US system [83].

384 Even though US technology can remove the fouled layer from the membrane surface and 385 increase the permeate flux Latt and Kobayashi [92], Matsumoto et al., [97] Muthukumaran et al., [124], its effect also depends on the feed solution matrix. For example, Chai et al. [104] used the US for cleaning polyacrylonitrile membrane after UF of dextran solution and found that the US technology could not remove the fouled layer from the membrane surface. This 
might be due to membrane vibration caused by the US waves, which increased bulk mass transfer [104]. Yu et al. [125] pointed out that applying the US for 10 mins could separate more

391 organic matter from the membrane surface. The US removed predominantly hydrophilic, high 392 molecular weight organic matter from the UF membrane. Concurrently, the US process had a 393 low effect on the accumulation of smaller molecular weight organic matter. Chen et al. [126]

394 studied the impact of particle characteristics on the ultrasonic control of membrane fouling.

395 The authors found that US cleaning was affected by the particle size and higher permeate flux recovery was observed when feed water contained large particles. Interestingly, the authors

397 reported membrane damage when the US was applied at a short distance from the membrane

398 surface under high pressure.

399 Some researchers have also investigated the effect of distance between the emitting surface of 400 the US and the membrane surface. The effect of US technology is fundamentally mechanical

401 (i.e., largely rely on the US transducer connection methods), so the highest permeate flux could 402 be achieved when the system is properly connected. Hengl et al. [127] found that at $8 \mathrm{~mm}$ 403 distance between the membrane surface and the blade, permeate flux increased by seven folds 404 without apparent damage to the membrane surface. It is believed that as the US transducer was 405 close to the membrane surface, the acoustic streaming could break down the polarization layer formed at the surface of the membrane [127]. Mackley and Sherman [128] used a direct 407 connection of the US as a cleaning technique and monitored particle deposition during UF sub408 millimeter particles. The authors found that the development of a cake fouling layer has 409 virtually ceased. In some cases, the close distance between the membrane surface and the US 410 emitting surface may cause damage to the membrane surface, especially with high US power. 411 Juang and Lin [109] found out that the polymeric membrane could get slightly damaged when 412 the US power was $80 \mathrm{~W}$, especially when the emitting horn surface was $10 \mathrm{~mm}$ below the 413 membrane surface. 
414 The US power is considered an important parameter due to the high effect on fouling removal

415 and water flux recovery $[92,97,124]$. , In general, permeate flux increases linearly with US

416 power up to a certain limit, after which no significant permeate flux improvement is observed.

417 Furthermore, operating at elevated US power could also damage membrane material [109].

418 Researchers also evaluated the coupling of US with backwash techniques. Chai et al. [34]

419 utilized an ultrasonic bath at $45 \mathrm{kHz}$ and $2.73 \mathrm{~W} / \mathrm{cm}^{2}$ to clean UF and MF membranes fouled

420 by peptones using a cross-flow filtration cell. The study revealed that cleaning fouled

421 membrane by combining US and backwash was better than the US alone. Furthermore,

422 Secondes et al. [83] and Naddeo et al. [129] reported removing emerging contaminants from

423 wastewater by activated carbon adsorption was about $90 \%$, but decreased over time. However,

424 the removal increased to almost $100 \%$ by applying the US, especially with a low frequency of $425 \quad 35 \mathrm{kHz}$.

426 The cleaning process by the US is also affected by the type of membrane material. Thus, 427 membranes made from the mixed ester of cellulose nitrate with cellulose acetate, nylon 6, and 428 polyvinylidene fluoride materials could be affected strongly by the US. In contrast, PES 429 material was only slightly affected [91]. The observed effects may be due to depolymerization 430 reactions enhanced by US irradiation via temporarily dispersing aggregated or permanently 431 breaking chemical bonds in polymeric chains [34]. Using low-frequency US, the 432 polyvinylidene fluoride is more resistant, and less change occurs on the surface [34].

\subsection{NF-US}

435 NF membrane fouling is a critical issue, as it is responsible for the deterioration of the 436 membrane performance [130, 131]. It was mentioned that the cost of fouling control is almost $43730 \%$ of the total operating cost [132]. US technology was proposed by many researchers as an 438 alternative cleaning technique to control NF membrane fouling $[79,112,113]$. US frequency 
is one of the main parameters that significantly affect the cleaning process. Tejal and Kaushik

440 [111] studied low-frequency US effects with two different modes (continuous and intermittent)

441 to remove the fouling accumulated on the membrane surface. They found that permeate flux

442 increased by $3 \%-4 \%$ when the US was applied continuously or intermittently for $160 \min$.

443 Continuous ultrasonic irradiation mode was more effective than the intermittent mode, but the

444 intermittent mode is still a better option when energy efficiency is considered [133, 134].

445 The second main parameter is the US's power, which could have a massive impact on the treatment process. Some researchers investigate the effect of high power on cleaning efficiency

447 and permeate flux enhancement. In a study by Renata et al. [135], high ultrasonic power of 240

448 W was applied to clean the NF membrane used in treating artichoke's solid wastes no 449 significant effect on the fouling layer was observed. Still, the highest chlorogenic acid recovery 450 was achieved when the US power was at $240 \mathrm{~W}$. Thombre et al. [79] used US technology for 451 cleaning fouled NF membranes. An ultrasonic power of $135 \mathrm{~W}$ achieved the best cleaning 452 process, while with a higher power of $150 \mathrm{~W}$, pitting and corrosion was detected on the 453 membrane surface. These results agree with a study by Muthukumaran et al. [106], who used $454300 \mathrm{~W}$ of US power. The authors also mentioned that permeate flux recovery of the NF 455 membrane increased by $90 \%$ in only 4 min of US.

It should be noted that applying a high power US increases the energy required for UF process and the major parts of US waves would be wasted [136]. Many researchers used the US to assist other cleaning techniques such as chemical and physical to avoid more energy waste. Liu 459 et al. [113] used the US-assisted chemical cleaning at a frequency of $25 \mathrm{kHz}$ and a power of 70 460 W. They found that US technology is a more effective way to improve chemical cleaning. They reported that the recovery rate reached up to $95.6 \%$ by applying US-assisted chemical cleaning.

462 Also, Jian et al. [112] used US-assisted chemical cleaning for fouling removal caused by 463 inorganic scales in arsenic-rich brackish water. Despite the increase in permeate flux, which 
reached $80 \%$ when the membrane was cleaned only by chemicals, the NF membrane water flux reached $99.99 \%$ when the US power intensity of $1 \mathrm{~W} / \mathrm{cm}^{2}$ was applied.

466

467

468

469

470

471

472

473

474

475

476

477

478

479

480

\subsection{RO-US}

Reverse osmosis (RO) is a well-established conventional desalination and water purification technology that uses a semipermeable membrane. RO technology is successfully used for the treatment of seawater and groundwater. Despite the advantages of RO technology in water purification $[87,88]$, it presents some disadvantages, such as sensitivity to $\mathrm{pH}$ and ionic strength, high energy consumption, and requirements for pre-treatment and membrane fouling [137]. The RO process requires high pressure (usually 0.2-1.7 MPa) for fresh and brackish water and 4-8.2 MPa for seawater treatment [138, 139]. The high-pressure demand translates into a higher pressure drop inside the module and reduced membrane permeability, which increases the pumping cost and alters rejection [140]. By applying high pressure, the membranes also become susceptible to fouling which clogs their pores [141] and reduces the permeate flux.

Researchers tested different chemical, physical, and US technology techniques to improve the permeate flux and reduce membrane fouling [39, 91, 109]; the latter technique is the subject of interest. Most US applications for alleviating RO fouling and improving permeate flux have been implemented in ultrasonic bath configuration on a lab-scale, as shown in Figure 5. Rarely, the US could cause damage to the RO membrane during the treatment process, which required more attention when US parameters were selected. Yong et al. [115] compared US application with acid and alkali agents for RO membrane cleaning while treating pharmaceuticals wastewater loaded by organic compounds. It was found that $50 \mathrm{kHz}$ frequency and $0.64 \mathrm{Wcm}^{-2}$ power were the most effective US cleaning parameters. However, membrane damage occurred when the US power was $0.636 \mathrm{Wcm}^{-2}$ and applied for $60 \mathrm{~min}$. The study highlighted two observations from the membrane damage test, including lengthy treatment time and dry storage 
490 RO-US system to reduce the fouling layer on the membrane surface and increase the permeate

491 flux without causing any damage to the membrane. Permeate flux improvement of the RO

492 process was attributed to the US cleaning. However, the increase in permeate flux of the RO

493 process by the US technology was not high enough. The authors explained this by the

494 deposition of $\mathrm{CaSO}_{4}$ due to hot spots created by US cavitation leading to a reduction in the

$495 \mathrm{CaSO}_{4}$ solubility [142]. A slight improvement is likely due to the advanced crystallisation stage

496 such that complete dislodgement was not possible, especially that US effects are contactless

497 with the membrane.

498 Sanderson et al. [80] suggested that integrating US treatment with the RO system during 499 operation could remove quickly built $\mathrm{CaCO}_{3}$ from the membrane surface, which facilitated 500 permeate flux improvement. The reason behind the quick fouling is that the $\mathrm{CaCO}_{3}$ might be transformed into more stable calcite crystals from a meta-stable aragonite form after $7 \mathrm{~h}$ of 502 operation due to the unstable ambient temperatures and pressure [143]. After fouling 503 accumulation, the membrane was cleaned with DI water backwash for $3 \mathrm{~h}$. This exercise did 504 not clean the membrane surface efficiently, as seen in Figure 6b. Hence, US irradiation was 505 used after $7 \mathrm{~h}$ of operation and was found to be efficient in almost complete removal of $\mathrm{CaCO}_{3}$ (Figure 6c). Although permeate flux increased after US application, it has never returned to the 507 permeate flux of a virgin membrane. The study also found that the cavitation of the US reduced 508 concentration polarization and the clogging of the membrane pores during the operation of the 509 RO system [144]. Using the US with biofouling remediation in membrane filtration, Raed et 510 al. [145] used a combination of US and heat (thermosonication) to remove biofilm developed 511 by E. coli from the RO membrane. The study showed that using thermosensation, the developed 512 biofilm was less dense with a smaller number of active microbes due to the biocidal effects 

starvation.
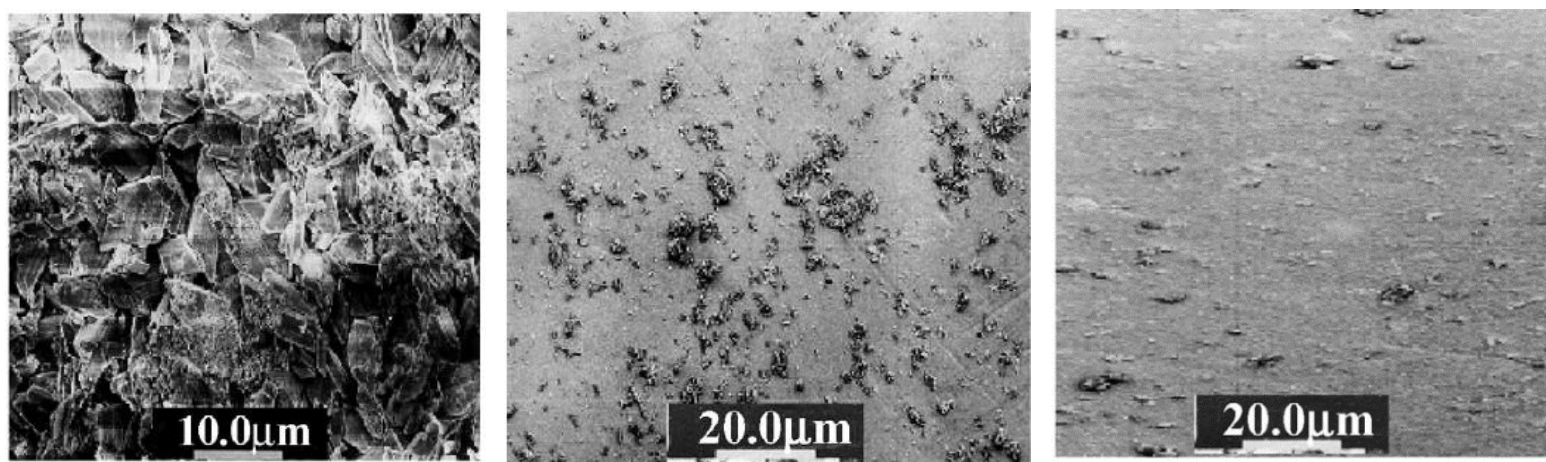

Figure 6: SEM images of a membrane surface: (a) after $7 \mathrm{hrs}$ of operation; (b) after $3 \mathrm{hrs}$ of cleaning with water; (c) after $0.5 \mathrm{~h}$ US treatment with dilute $\mathrm{HCl}$ [80]

\section{US application with membrane bioreactor systems (MBR)}

517 The MBR can be categorized into two types, namely aerobic membrane bioreactors (AeMBRs)

518 and anaerobic membrane bioreactors (AnMBRs) [146-148]. Even though air (in AeMBR

519 processes) can reduce the membrane fouling by scouring the membrane surface [149], the

520 membrane bioreactor system was stressed due to fouling deposition on the membrane surface.

521 As such, integrating the US with an MBR was introduced prominently to tackle the fouling problem. Jai et al. [150] suggested and tested catalytic US oxidation (CUO) with membrane bioreactor for treating real wastewater. Integrating the US with catalytic oxidation resulted in

524 a high removal of total organic carbon (TOC) and improved biodegradability of recalcitrant

525 contaminants in wastewater at US frequencies of $35-65 \mathrm{kHz}$ [151]. The study of Pendashteh et al. [152] utilized the US process for cleaning the MBR system, which was used for treating synthetic hypersaline oily wastewater samples. The US cleaning removed the fouled layer and recovered the permeate flux for a long time.

529 In a study carried out by Xu et al. [153], an integrated AnMBR-US system (Figure 7) was

530 applied for the digestion of sludge under high volatile solids (VS) at a loading rate of (3.7 $\mathrm{gVS} / \mathrm{L}$ d) for 54 days. Although the US process could successfully control the cake layer 
532 formation on the membrane surface, it had only a slight effect on the gel layer removal formed

533 by the adsorption of proteins and humic compounds. Sui et al. [154] tested intermittent US

534 applications with an MBR system to reduce fouling development on the membrane surface.

535 This study found that increasing the sludge concentration in the reactor increased the need for

536 longer ultrasonic irradiation. The study pointed out that the US irradiation had a small negative

537 impact on the anaerobic bacteria activity; however, this did not affect chemical oxygen demand

538 (COD) removal. Ruiz et al. [155] studied the effect of ultrasonic frequencies in a range of 20

$539 \mathrm{kHz}-40 \mathrm{kHz}$ on membrane integrity, process performance and effluent quality using four

540 different UF modules. The fouled membrane received two different cleanings: the US for $3 \mathrm{~s}$

541 every 3 min with the power of $150 \mathrm{~W}$ and various frequencies or backwash for 1 min with $5 \mathrm{~s}$

542 of aeration. The highest cleaning effect was observed with a frequency of $20 \mathrm{kHz}$ with no sign

543 of damage to the membrane surface.

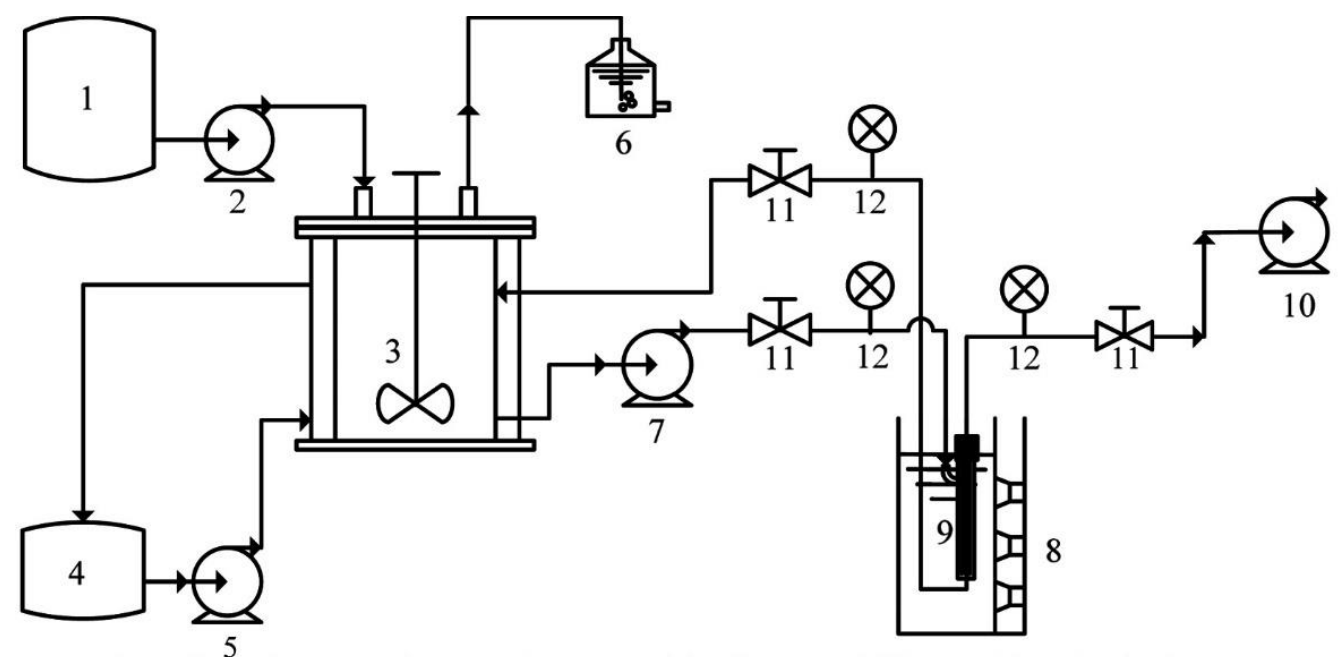

1. Feed stock tank 2. Feed pump 3. Anaerobic digester (CSTR with mixer) 4. Hot water bath 5. Hot water recirculation pump 6. Gas collector 7. Mixed liquor recirculation pump 8. Ultrasonic cleaning equipment 9. Hollow fiber membrane 10. Suction pump 11. Valve 12. Manometer

Figure 7: The flow diagram of the US-AnMBR [153].

545 Another study by Ruiz et al. [156] found that even though the high US power of $300 \mathrm{~W}$ and $546400 \mathrm{~W}$ increased the turbidity of the effluent from 2 NTU to $20 \mathrm{NTU}$, other parameters like 547 viscosity, colour, effluent COD and total suspended solids concentration did not change. This 
could be due to the deflocculation of the sludge under ultrasonic irradiation [157]. Li et al.

[158] used US for cleaning the fouled membrane in a submerged membrane bioreactor under different US frequencies of $25 \mathrm{kHz}-90 \mathrm{kHz}$, and applied power of $200 \mathrm{~W}-300 \mathrm{~W}$. The results of this study showed that the US could reduce the quantity of the sludge produced with the MBR system. The higher the transmembrane pressure, the higher the fouling layer on the membrane surface. Hence, fouling removal by the US would reduce the transmembrane pressure in the filtration process.

Sui et al. [159] applied US technology to clean the membrane used in an anaerobic membrane bioreactor. It was noted that the US effect on fouling diminished when the crossflow velocity was greater than $1 \mathrm{~m} / \mathrm{s}$ as the fouled membrane could be cleaned by hydrodynamic forces. On the other hand, the total filtration resistance was drastically improved when applying the US with a crossflow velocity of less than $1 \mathrm{~m} / \mathrm{s}$, and the membrane fouling rate was $8.33 \times 10^{6} \mathrm{~m}^{-}$

$560{ }^{1} \mathrm{~s}^{-1}$ and $3 \times 10^{7} \mathrm{~m}^{-1} \mathrm{~s}^{-1}$. The study reported a stable low total filtration resistance for one week 561 with ultrasonic power of $150 \mathrm{~W}$. Abdurahman and Azhari [160] tested US-AnMBRs to treat 562 oil mill effluent with multi-frequency ultrasonic transducers. The study found that this system 563 could achieve COD removal of $98.7 \%$ with a hydraulic retention time of 4 days and maximum methane production of $0.47 \mathrm{~L} / \mathrm{g}$ COD day. Similar findings were also reported by Shafie et al. [161]. The authors indicated that the violent mechanical effects of the US are responsible for membrane damage and the interaction of the strong oxidants produced due to bubbles collapse

567 with membrane materials. Liu et al. [162] investigated the effect of the online US-MBR system 568 on removing organic pollutants from the membrane surface. The study found that the activity of the biological process was increased when the US was applied with the power of $10 \mathrm{~W}$. This increment in the activity of biological was due to the turbulences accompanying propagation

571 of US waves and the cavitational effects, which can increase the mass transfer by moving the 572 particles in a fluid and increase the production of the extracellular enzyme. 
573 Yoon et al. [163] studied the effect of ex-situ US on removing sludge production in the MBR 574 system using submerged hollow fibre membrane with the power of $600 \mathrm{~W}$ and a frequency of

$57520 \mathrm{kHz}$. This study found that the mixed liquor suspended solids (MLSS) were kept constant 576 in the range of $7000 \mathrm{mg} / \mathrm{L}-8000 \mathrm{mg} / \mathrm{L}$ when the US was applied, while the range of the MLSS 577 increased from $7000 \mathrm{mg} / \mathrm{L}$ to $13700 \mathrm{mg} / \mathrm{L}$ without US application. This is attributed to the 578 virtue of the US in preventing excess sludge production. Joshi and Parker [164] used the US as 579 a pretreatment with hydrogen peroxide to treat waste stream before digesting in a submerged 580 anaerobic membrane bioreactor. The study showed that COD solubilization increased by about $58140 \%$ when the hydrogen peroxide dose was $50 \mathrm{~g} / \mathrm{kg}$ TS and sonication operated for $60 \mathrm{~min}$.

582 Wu et al. [165] investigated the US irradiation effect on the liquor properties of activated sludge 583 using a power range of $40 \mathrm{~W}-300 \mathrm{~W}$, volatile suspended solids concentration of $6 \mathrm{~g} / \mathrm{L}$, and a concentration range of mixed liquor suspended solids of the activated sludge of $10 \mathrm{~g} / \mathrm{L}-12 \mathrm{~g} / \mathrm{L}$. The results showed that US treatment with an intensity of up to $2 \mathrm{~kJ} / \mathrm{mL}$ could increase the width of particle size distribution and the biodegradability of the activated sludge. Pardo et al.

587 [166] used US combined with ozonation $\left(\mathrm{O}_{3}-\mathrm{US}\right)$ to treat wastewater prior to the submerged MBR. The study found that the decomposition of the organic compounds was increased due to the $\mathrm{O}_{3}$-US treatment, resulting in a decrease in the microorganism's growth. Hence, the concentration of extracellular polymeric substances was reduced by around 50\%. Overall, US

591 technology could improve MBR performance by increasing nutrients degradability. Improving 592 mass transfer across the membrane and reducing membrane fouling. However, the positive 593 effects can only be achieved if the proper US parameters are selected.

\section{5. Integrating US with emerging membrane technologies}

\section{5.1. Ultrasound- Forward Osmosis (US-FO)}

596 The FO process uses natural osmotic pressure difference of feed solutions of different 597 concentrations to transfer water through a semipermeable membrane from the higher solute 
concentration side to the lower solute concentration side. FO is far more energy-efficient and lower membrane fouling than the RO process [167]. However, the FO process also suffers from membrane fouling, especially when treating a low-quality feed solution. Integrating US

601 technology with FO could be an attractive solution to this problem. Heikkinen et al. [168] tested

602 the US-assisted FO process and found that permeate flux ofFO system was increased after 603 applying US technology. The US irradiation improves the FO process performance by reducing 604 both internal (ICP) and external (ECP) concentration polarization effects (Table 2).

605 Choi et al. [169] found that US combined with FO decreased the concentration polarization 606 occurrence and membrane fouling and improved membrane efficiency. However, the US effect 607 on the membrane's durability is not obvious, and the outcome of previous studies on this issue 608 has been contradictory. Chanukya and Rastogi [170] investigated the US effect on FO 609 membrane concentration polarization while treating fruit juice and natural colorant. The 610 authors found that US applications can increase permeate flux due to ECP mitigation on the 611 feed side and ICP in the support layer. Despite the permeate flux of the FO membrane enhanced 612 by US technology when the concentration of sucrose was up to 5\%, the authors found that US 613 was not able to mitigate the ECP and prevent fouling layer formation when pectin was present 614 in the feed solution which resulted in a reduction in the permeate flux. Chio et al. [171] also 615 studied the effect of US on ICP during the FO process with flat sheet membrane by utilizing 616 different US frequencies of $25 \mathrm{kHz}, 45 \mathrm{kHz}$ and $72 \mathrm{kHz}$ and power of $10 \mathrm{~W} 70 \mathrm{~W}$. The authors 617 found that US technology could significantly mitigate the ICP by improving the diffusion rate 618 of a draw solution. The authors also reported that membrane damage was observed at the US 619 frequency of $25 \mathrm{kHz}$ and $50 \mathrm{~W}$ of the applied power, leading to a $3000 \%$ increase in permeate 620 flux. This damage is likely caused by changes in membrane properties which were significantly 621 affected by the US. The low-frequency US irradiation was proposed by Wang et al.[172] to 622 improve the permeate flux of the FO process with TFC PES-based polymeric membranes. The 
623 authors found that the US significantly improved the FO process permeate flux via mitigating

624 ECP effect. Lee et al. [173] studied the effect of US cleaning on the FO membrane fouled by

625 activated sludge was investigated. An effective fouling removal was also observed when the

626 US was combined with flushing. Thus, $40 \%$ of permeate flux was recovered when the US was

627 used for $60 \mathrm{~s}$, while with flushing only, the permeate flux of the FO was recovered only by

$62829 \%$ [153]. Nguyen et al. [174] used the US to control the fouling on the FO membrane. The

629 study found that the sludge concentration reached $20,400 \mathrm{mg} / \mathrm{L}$ and $28,400 \mathrm{mg} / \mathrm{L}$ from the

630 initial sludge concentration of $3,000 \mathrm{mg} / \mathrm{L}$ and $8,000 \mathrm{mg} / \mathrm{L}$ with $40 \mathrm{kHz}$ after 22 hours.

631 However, from an energy requirements perspective, this method is not an energy-efficient

632 technique.

633 5.2. $U S-M D$

634 5.3. Ultrasound-Air Gap Membrane Distillation (US-AGMD)

635 AGMD has many advantages, including cost efficiency [1], lower chemical demand [175], no

636 feedwater pretreatment [40] and low membrane damage [176, 177]. Moreover, AGMD is

637 capable of separating all non-volatile matter under moderate operating conditions that ensure

638 system reliability and durability with no requirement for additional complex condensers [178,

639 179], which are needed in vacuum membrane distillation (VMD) and sweeping gas membrane

640 distillation (SGMD) [180]. Although AGMD has witnessed many physical developments, the

641 permeate flux of the AGMD is still low compared to some other membrane separation

642 processes. Another limitation of the AGMD system is that the fouling layer is quickly built on

643 the membrane surface due to the relatively big pore size of the membrane $(0.2 \mu \mathrm{m}-1.0 \mu \mathrm{m})$

644 [181]. This layer can prevent water vapour from crossing the membrane, resulting in low

645 permeate flux. The AGMD process can be integrated with US technology to overcome fouling

646 and improve water flux, as seen in Figure $8[35,59,180]$. Technically, the US energy could be

647 converted to heat which can reduce the heat transfer loss across the membrane and therefore 
649 US for mitigating fouling problem in MD processes, including AGMD. Although the US has

650 a benign environmental effect, it can increase the water treatment energy consumption. Also,

651 applying high power of US, waves may damage the membrane surface [39].

652

653 Table 2. Effect of US technology on FO and MD performance.

\begin{tabular}{|c|c|c|c|c|c|c|c|c|}
\hline $\begin{array}{c}\text { Connection } \\
\text { type }\end{array}$ & $\begin{array}{c}\text { Module } \\
\text { type }\end{array}$ & Parameters & $\begin{array}{c}\text { Feed } \\
\text { concentration } \\
\text { Units should } \\
\text { be here }\end{array}$ & $\begin{array}{c}\text { Initial } \\
\text { water } \\
\text { flux, } \\
\mathrm{kg} / \mathrm{m}^{2} \cdot \mathrm{h}\end{array}$ & $\begin{array}{l}\text { US water } \\
\text { flux, } \\
\mathbf{k g} / \mathbf{m}^{2} \cdot \mathbf{h}\end{array}$ & $\begin{array}{l}\text { Percentage } \\
\text { increase }\end{array}$ & $\begin{array}{c}\text { Rejection, } \\
\%\end{array}$ & Ref \\
\hline \multirow{2}{*}{ In- situ } & \multirow{2}{*}{ AGMD } & \multirow{2}{*}{$\begin{array}{l}\text { Feed temp: } 50^{\circ} \mathrm{C} \text {, coolant } \\
\text { temp: } 20^{\circ} \mathrm{C} \text {, feed flow: } \\
60 \mathrm{~L} / \mathrm{h} \text {, coolant flow: } \\
200 \mathrm{~L} / \mathrm{h} \text {, US power: } \\
24 \mathrm{~W} / \mathrm{m}^{2} \text {, US frequency: } \\
20 \mathrm{kHz}\end{array}$} & $\begin{array}{l}\text { natural } \\
\text { groundwater } \\
12960 \mu \mathrm{S} / \mathrm{cm}\end{array}$ & 0.6 & 1.2 & $100 \%$ & 99.98 & \multirow[t]{2}{*}{ [39] } \\
\hline & & & $\begin{array}{l}\text { RO reject } \\
\text { water } \\
3790 \mu \mathrm{S} / \mathrm{cm}\end{array}$ & 0.5 & 1.0 & $100 \%$ & 99.98 & \\
\hline \multirow[t]{2}{*}{ Ex-situ } & \multirow[t]{2}{*}{ AGMD } & \multirow{2}{*}{$\begin{array}{l}\text { Feed temp: } 35 \text { to } 75^{\circ} \mathrm{C} \text {, } \\
\text { coolant temp: } 25^{\circ} \mathrm{C} \text {, feed } \\
\text { concentration: feed flow: } \\
0.063 \mathrm{~m} / \mathrm{s} \text {, US power: } 30 \mathrm{~W} \text {, } \\
\text { US frequency: } 20 \mathrm{kHz}\end{array}$} & $\begin{array}{l}\text { sodium } \\
\text { chloride } 0.5 \\
\text { wt. } \%, 1 \text { wt. } \% \\
\text { and } 5 \text { wt. } \%\end{array}$ & N/A & 1.06 & $5 \%-30 \%$ & N/A & \multirow[t]{2}{*}{ [180] } \\
\hline & & & Tap water & N/A & 1.15 & $5 \%-30 \%$ & N/A & \\
\hline \multirow{3}{*}{ Ex-situ } & \multirow{3}{*}{ DCMD } & \multirow{3}{*}{$\begin{array}{l}\text { Feed temp: } 35^{\circ} \mathrm{C} \text {, coolant } \\
\text { temp: } 20^{\circ} \mathrm{C} \text {, feed flow: } \\
0.25 \mathrm{~m} / \mathrm{s} \text {, coolant flow: } \\
1.0 \mathrm{~m} / \mathrm{s} \text {, US power: } 260 \mathrm{~W} \text {, } \\
\text { US frequency: } 20 \mathrm{kHz}\end{array}$} & $\begin{array}{ll}\mathrm{CaSO}_{4} & 2000 \\
\mathrm{mg} / \mathrm{L} & \end{array}$ & 0.415 & 0.915 & $100 \%$ & 100 & \multirow{3}{*}{ [182] } \\
\hline & & & $\begin{array}{l}\mathrm{CaCO}_{3} \\
100 \mathrm{mg} / \mathrm{L}\end{array}$ & 0.95 & 0.96 & $1 \%$ & 100 & \\
\hline & & & $\mathrm{SiO}_{2} 150 \mathrm{mg} / \mathrm{L}$ & 0.8 & 1.0 & $20 \%$ & 100 & \\
\hline \multirow{5}{*}{ Ex-situ } & \multirow{5}{*}{ DCMD } & \multirow{5}{*}{$\begin{array}{l}\text { Feed temp: } 53^{\circ} \mathrm{C} \text {, coolant } \\
\text { temp: } 20^{\circ} \mathrm{C} \text {, feed flow: } \\
0.25 \mathrm{~m} / \mathrm{s} \text {, coolant flow: } \\
1.0 \mathrm{~m} / \mathrm{s} \text {, US power: } 260 \mathrm{~W} \text {, } \\
\text { US frequency: } 20 \mathrm{kHz}\end{array}$} & $\begin{array}{l}\text { Humic acid } \\
\text { (HA) } 10 \mathrm{mg} / \mathrm{L}\end{array}$ & 1.76 & $\begin{array}{l}\mathrm{NO} \\
\text { experiment }\end{array}$ & N/A & 99.97 & \multirow{5}{*}{ [183] } \\
\hline & & & $\begin{array}{l}\text { Humic acid } \\
\text { (HA) } 50 \mathrm{mg} / \mathrm{L}\end{array}$ & 1.65 & 2.1 & $30 \%$ & 99.97 & \\
\hline & & & $\begin{array}{l}\mathrm{HA} 50 \mathrm{mg} / \mathrm{L}+ \\
\mathrm{CaCl}_{2} 2 \mathrm{mM} .\end{array}$ & 0.9 & 0.99 & $30 \%$ & 99.97 & \\
\hline & & & $\begin{array}{l}\mathrm{HA} 50 \mathrm{mg} / \mathrm{L}+ \\
\mathrm{CaCl}_{2} 10 \mathrm{mM} .\end{array}$ & 0.85 & 0.97 & $30 \%$ & 99.97 & \\
\hline & & & $\begin{array}{l}\text { HA } 50 \mathrm{mg} / \mathrm{L}+ \\
\mathrm{CaCl}_{2} 20 \mathrm{mM} .\end{array}$ & 0.76 & 0.95 & $30 \%$ & 99.97 & \\
\hline Ex-situ & DCMD & $\begin{array}{l}\text { Feed temp: } 53^{\circ} \mathrm{C} \text {, coolant } \\
\text { temp: } 20^{\circ} \mathrm{C} \text {, feed flow: } \\
0.25 \mathrm{~m} / \mathrm{s}, \text { coolant flow: }\end{array}$ & $\begin{array}{l}\text { silica } \\
\text { concentration } \\
150 \mathrm{mg} / \mathrm{L}\end{array}$ & 1.5 & 2.1 & $43 \%$ & 100 & [38] \\
\hline
\end{tabular}




\begin{tabular}{|c|c|c|c|c|c|c|c|c|}
\hline & & $\begin{array}{l}\text { 1.0m/s, US power: } 260 \mathrm{~W}, \\
\text { US frequency: } 20 \mathrm{kHz}\end{array}$ & & & & & & \\
\hline Ex-situ & $\mathrm{FO}$ & $\begin{array}{l}\text { Feed temp: } 27^{\circ} \mathrm{C} \text {, feed } \\
\text { flow: } 150 \mathrm{ml} \min ^{-1} \text {, US } \\
\text { frequency: } 30 \mathrm{kHz}\end{array}$ & $\begin{array}{l}\text { Fruit juice and } \\
\text { natural } \\
\text { colorant }\end{array}$ & $\begin{array}{l}10 \mathrm{~lm}^{-} \\
{ }^{2} \mathrm{~h}^{-1}\end{array}$ & $12 \mathrm{~lm}^{-2} \mathrm{~h}^{-1}$ & 20 & N/A & [170] \\
\hline Ex-situ & FO & $\begin{array}{l}\text { Feed temp: } 20^{\circ} \mathrm{C} \text {, feed } \\
\text { flow: } 0.25 \mathrm{~m} / \mathrm{s} \text {, US power: } \\
10-70 \mathrm{~W} \text {, US frequency: } \\
25,45,72 \mathrm{kHz}\end{array}$ & $\mathrm{NaCl}$ & $\begin{array}{l}3.7 \\
\mathrm{LMH}\end{array}$ & 8.4 LMH & 129 & N/A & [171] \\
\hline Ex-situ & FO & $\begin{array}{l}\text { Feed temp: } 20^{\circ} \mathrm{C}, \text { feed } \\
\text { flow: } 1 \mathrm{~L} / \mathrm{min}, \text { pressure } \\
\text { 5bar, US power: } 30 \mathrm{~W}, \text { US } \\
\text { frequency: } 72 \mathrm{kHz}\end{array}$ & $\begin{array}{l}\text { calcium } \\
\text { sulfate }\end{array}$ & $\begin{array}{l}10 \\
\mathrm{LMH}\end{array}$ & $16 \mathrm{LMH}$ & 60 & N/A & [169] \\
\hline Ex-situ & $\mathrm{FO}$ & $\begin{array}{l}\text { Feed temp: } 40^{\circ} \mathrm{C}, \text { feed } \\
\text { flow: } 1.2 \mathrm{~L} / \mathrm{min} \text {, pressure } \\
3.1 \mathrm{bar} \text {, US power: } 50- \\
300 \mathrm{~W} \text {, US frequency: } \\
22 \mathrm{kHz}\end{array}$ & $\begin{array}{l}\text { sodium } \\
\text { sulphate }\end{array}$ & $\begin{array}{l}11 \\
\mathrm{LMH}\end{array}$ & $23 \mathrm{LMH}$ & 110 & N/A & [168] \\
\hline Ex-situ & FO & $\begin{array}{l}\text { Feed temp: } 25^{\circ} \mathrm{C} \text {, feed flow } \\
\text { velocity: } 3.8 \mathrm{~m} / \mathrm{s} \text {, pressure } \\
3.1 \text { bar, US power: } 1800 \mathrm{~W} \text {, } \\
\text { US frequency: } 57 \mathrm{kHz}\end{array}$ & $\begin{array}{l}\text { activated } \\
\text { sludge }\end{array}$ & $\begin{array}{l}6.5 \mathrm{Lm}^{-2} \\
\mathrm{~h}^{-1}\end{array}$ & $\begin{array}{l}8.5 \mathrm{Lm}^{-2} \mathrm{~h}^{-} \\
1\end{array}$ & 40 & N/A & [173] \\
\hline Ex-situ & $\mathrm{FO}$ & $\begin{array}{l}\text { Feed temp: } 25^{\circ} \mathrm{C}, \text { feed } \\
\text { flow: } 280 \mathrm{~mL} / \mathrm{min} \text {, pressure } \\
\text { 3.1bar, US power: } 1800 \mathrm{~W} \text {, } \\
\text { US frequency: } 40 \mathrm{kHz}\end{array}$ & $\begin{array}{l}\text { waste } \\
\text { activated } \\
\text { sludge }\end{array}$ & N/A & N/A & N/A & 98 & [174] \\
\hline Ex-situ & $\mathrm{FO}$ & $\begin{array}{l}\text { Feed temp: } 20^{\circ} \mathrm{C} \text {, feed flow } \\
\text { velocity: } 0.28 \mathrm{~m} / \mathrm{s}, \quad \text { US } \\
\text { power: } 0.2 \text { to } 0.8 \mathrm{~W} / \mathrm{cm}^{2} \text {, } \\
\text { US frequency: } 40 \mathrm{kHz}\end{array}$ & $\begin{array}{l}\text { sodium } \\
\text { chloride } \\
\text { solution }\end{array}$ & $\begin{array}{l}18 \\
\mathrm{LMH}\end{array}$ & $20 \mathrm{LMH}$ & 18 & 100 & [172] \\
\hline
\end{tabular}




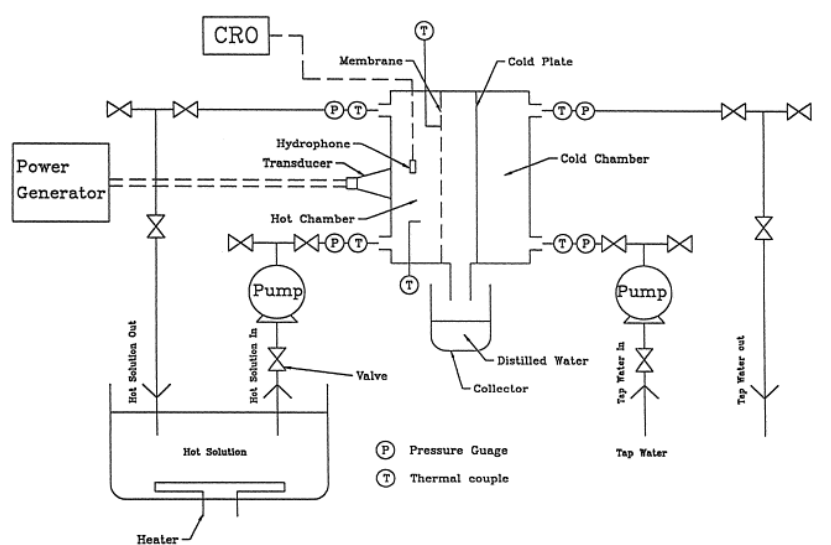

(a)

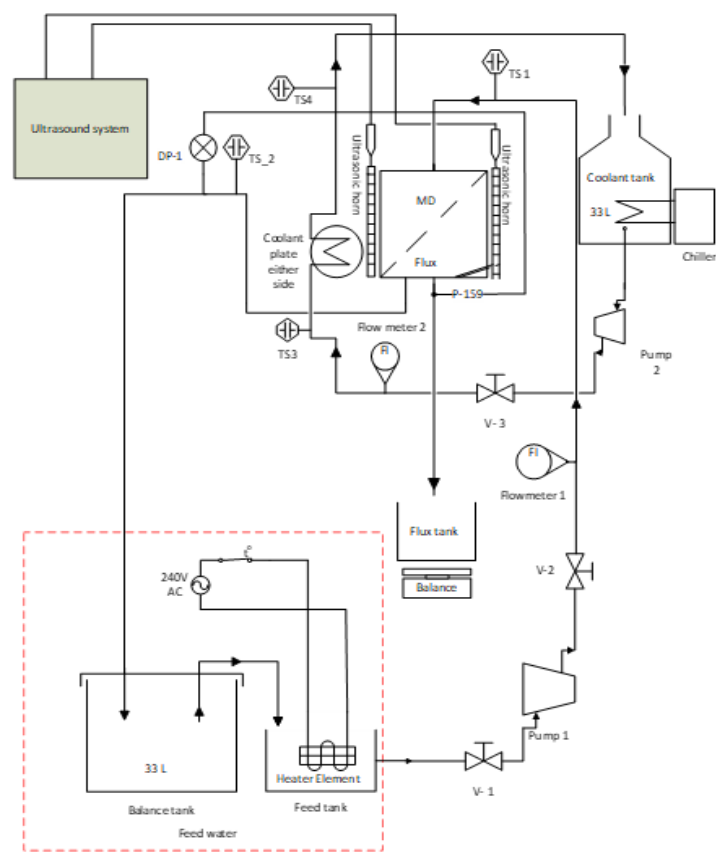

(b)

Figure 8: Shows the AGMD-US system, (a) ex-situ [180] and (b) in-situ [39].

656

657 The possibility of integrating AGMD with US technology was proposed and tested by Zhu et

658 al. [180] for two types of feed solutions. The study found that the higher the US irradiation power, the higher the permeate flux would be. It is also found that a higher feed temperature can improve the permeate flux of the AGMD with the same US intensity. The reason behind

661 this increment is that water flux in the AGMD process depends on the temperature difference 662 between both sides of the membrane. The permeate flux of the AGMD increased when the US 663 was operated for 10 min each 30 min, demonstrating its ability to break the cake layer built on 664 the membrane surface [40]. Another study by Naji et al. [39] designed an integrated US-AGMD system to treat natural groundwater $(3,970 \mu \mathrm{S} / \mathrm{cm})$, and RO rejects water $(12,760 \mu \mathrm{S} / \mathrm{cm})$. They

666 found that the US technology could bring a 100\% improvement in permeate flux $100 \%$ by 667 removing the fouling cake layer and improving mass transfer across the membrane. The study 668 used a new technique in which US transducers is directly connected to the spacers on both sides 669 of the membrane (in-situ). 
671 Another MD process that has been frequently probed in water desalination is direct contact 672 membrane distillation (DCMD). Its advantages include low working temperatures, operation 673 at atmospheric pressure and high salt rejections [184-186]. However, DCMD performance is 674 accompanied by membrane fouling which significantly impends the permeate flux and 675 increases operation costs. Therefore, to improve the permeate flux of the DCMD and reduce 676 fouling on the membrane surface, it is suggested to integrate DCMD with US technology, as 677 shown in Figure 9. Several researchers focused on integrating DCMD with the US to overcome 678 membrane fouling and improve the permeate flux [38, 59, 182, 183]. Hou et al. [182] designed 679 and tested four transducers located outside the water bath to treat three different synthetic water 680 samples containing $\mathrm{CaSO}_{4}, \mathrm{CaCO}_{3}$, and $\mathrm{SiO}_{2}$. The study found that the permeate flux of the 681 DCMD reduced by $55 \%$ when $\mathrm{CaSO}_{4}$ concentration increased from $1 \mathrm{mg} / \mathrm{L}$ to $4 \mathrm{mg} / \mathrm{L}$ due to 682 the precipitation of $\mathrm{CaSO}_{4}$ salt on the membrane surface [182]. In another experiment, 20\% reduction of permeate flux was achieved when feed solution contained $\mathrm{Na}_{2} \mathrm{SiO}_{2}$ due to 684 formation and deposition of colloidal polysilicic acid on the membrane surface. However, 685 when the US was applied, no permeate flux decline was observed due to US cleaning of the 686 membrane surface. The rejection rates in all experiments with and without US treatment were 687 around $99.99 \%$.

688 Furthermore, the US exhibited a more pronounced effect on permeate flux recovery at a higher 689 salt concentration factor. The authors also showed that the US did not affect the membrane 690 integrity since the ex-situ US connection kept the emitting surface away from the membrane 691 surface. Another study by Hou et al. [38] used a PTFE membrane for treating synthetic water 692 containing silica with a concentration of $150 \mathrm{mg} / \mathrm{L}$. During DCMD experiments, the feed water was not diluted while the silica was added to the DCMD-US experiments. The study found that 694 the permeate flux during the stand-alone DCMD process decreased by around $20 \%$ when the 695 silica concentration factor peaked at 4. Contrarily to this, permeate flux decreased during the 
696 DCMD-US process was insignificant and comprised $\sim 97 \%$ of the virgin membrane permeate

697 flux. The SEM images (Figures 10a-c) confirmed an amorphous silica-scaling layer formed on

698 the membrane surface after the stand-alone DCMD process. In comparison, SEM images of

699 the PTFE membrane surfaces used in DCMD-US experiments had no silica layer on the

700 membrane surface. Figures 10d-e demonstrate the effectiveness of US technology to remove

701 fouling materials from the membrane surface even when $\mathrm{Ca} 2+$ ions exacerbated membrane

702 fouling. Furthermore, permeate flux of the combined US-DCMD system was $2 \mathrm{~kg} / \mathrm{m}^{2}, 34 \%$

703 higher than the permeate flux observed with stand-alone DCMD. Another study by Hou et al.

704 [183] utilized PTFE membrane to treat synthetic feed, which incorporated $50 \mathrm{mg} / \mathrm{L}$ of humic 705 acids (HA) and $\mathrm{CaCl}_{2}$ in a range of $2 \mathrm{mM}-20 \mathrm{mM}$. The authors found that US irradiation 706 enhanced permeate flux by more than $30 \%$ without affecting HA rejection. In addition, 707 permeate flux enhancement increased with a concentration factor

708

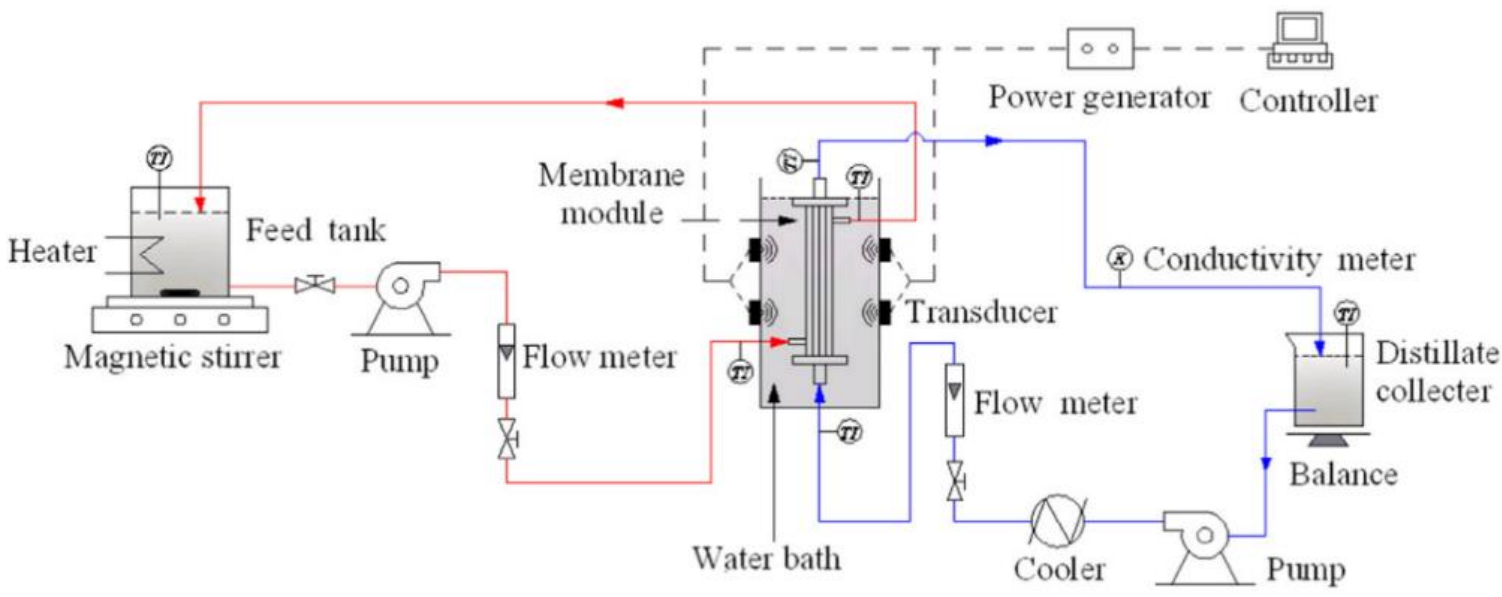

Figure9: DCMD integrated with US [38]. 


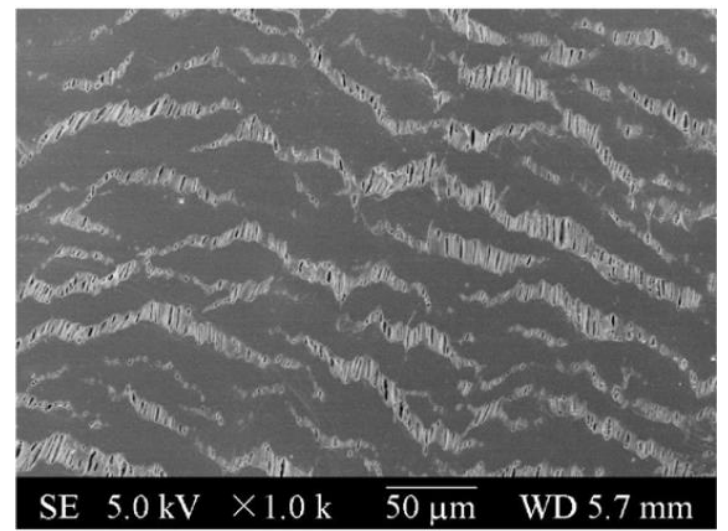

(a)

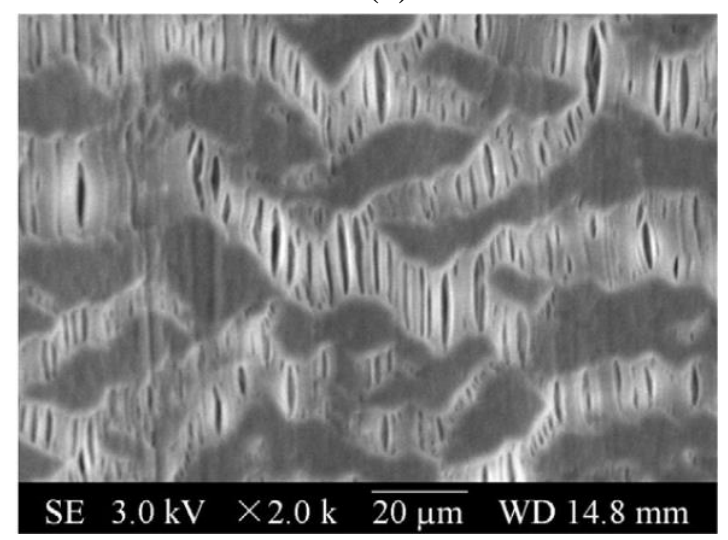

(c)

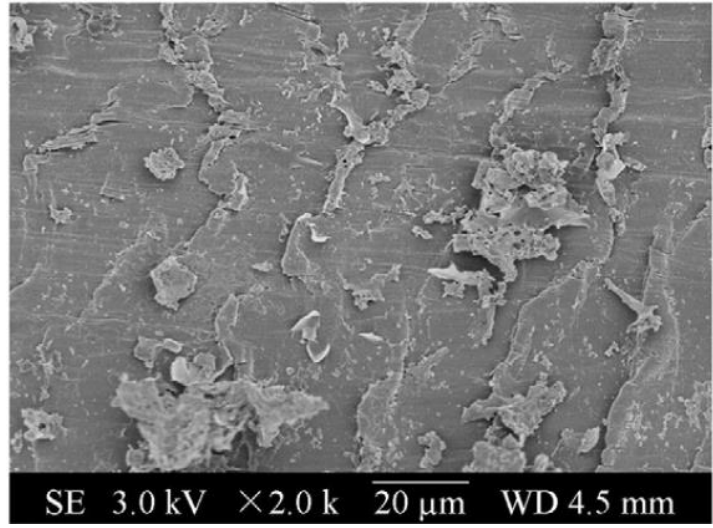

(b)

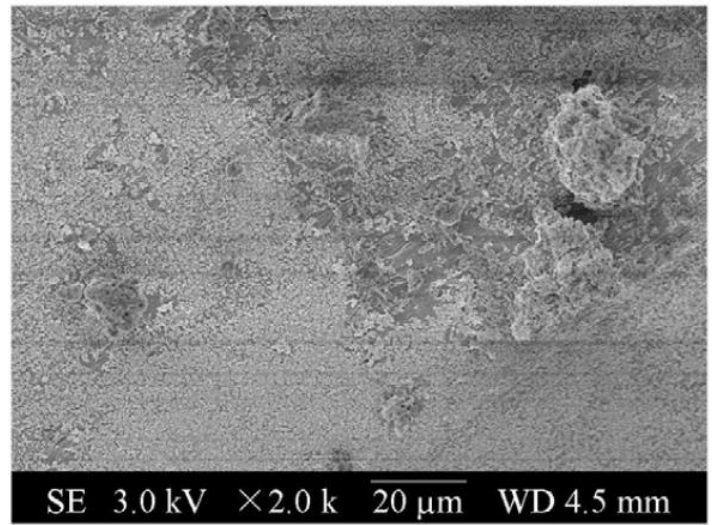

(d)

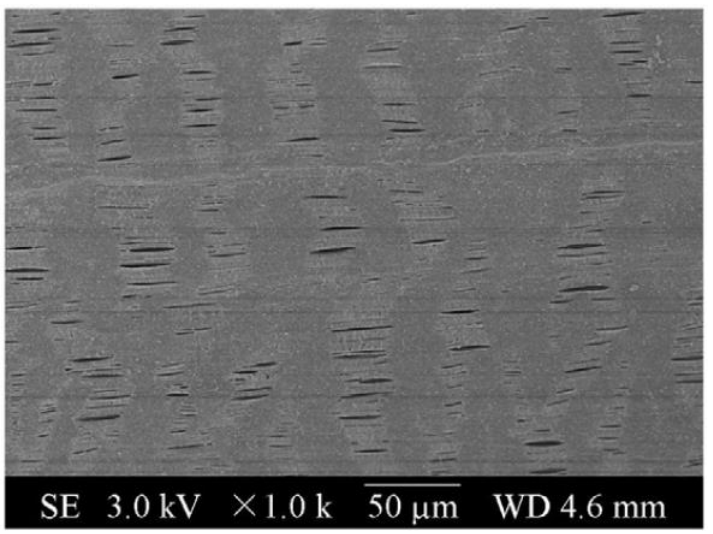

(e)

Figure 10: SEM images of the PTFE membrane, (a) virgin PTFE membrane, (b) PTFE membrane after silica fouling, (c) PTFE membrane after silica solution concentration with US irradiation, (d) after silica solution concentration experiment running $30 \mathrm{~min}$ in the presence of $\mathrm{Ca}^{2+}$ ions, (e) after silica solution concentration experiment in the presence of US irradiation [38].

\section{6. Overview of ultrasound effect on membrane properties}

713 The discussion regarding the change in membrane properties upon exposure to ultrasound

714 effect has been mainly focused on membrane physical structure as discussed in previous

715 sections. It is important to ponder about this point beyond optical or microscopic examination. 
716 In general, membranes can be classified into organic membranes that absorb the mechanical

717 effects of ultrasound (e.g. shock wave, streaming) and inorganic that reflect the energy

718 produced from the mechanical effects of ultrasound. For both membrane categories, ultrasound

719 treatment can change their roughness and porosity. Several studies reported pores enlargement

720 and structural damage after ultrasound treatment for polymeric membrane as mentioned in

721 Table 1. However, the extent of ultrasonic effect on polymeric membrane structure varies depending on their chemical structure. For instance, Masselin et al. [187] reported crevices in PES membrane, while PVDF and PAN membranes did not show sign of structural degradation under the same ultrasound treatment conditions. Pitting of inorganic membrane surface is a possible scenario when treated with ultrasound especially at high power and short distance between emitting surface and membrane surface. Once the roughness of membrane surface increase, the possibility of heterogeneous cavitation on membrane surface increases. This in turn can deteriorate the membrane structure through the continuous oscillation of heterogeneous cavitation bubbles [106].

730 The impact of the physical effects of ultrasound on membrane properties have adequately been studied, however the impact of the chemical effects is rarely discussed in the literature. It is important to remember here that high frequency ultrasound produces more chemical effects (i.e. generation of free radicals) compared to low frequency. Hence, high frequency ultrasound is expected to cause change in membrane surface chemistry. It was reported that the production of radicals such as $\mathrm{OH} \bullet \mathrm{O} \bullet$ and oxidant agents such as $\mathrm{H}_{2} \mathrm{O}_{2}$ may cause chemical bonds scission of membrane materials [51]. The quantity and the aggressiveness of produced radicals and oxidants depends on many factors such as power intensity and presence or absence of radicals scavenging and promoting agents. For example, the presence of $\mathrm{Fe}^{+2}$ facilitated the degradation of ionomer membrane, Nafion ${ }^{\circledR} 117$ through the hydroperoxyl radical attack on main and side

740 chain of the polymer [188]. The produced free radicals with ultrasound can also interact with 
the membrane surface altering its properties. Free radicals can interact with the dissolved oxygen and the carbonous structure of organic membrane producing carboxyl and carbonyl groups that makes the membrane more hydrophilic [189]. In order to accurately capture the changes that occur in membrane properties, long term tests and advanced analytical chemical examinations are recommended to be applied as such changes can be subtle and hard to detect in short-term tests and crude analyses.

\section{Membrane-assisted ultrasound technology: recommendations for future research directions}

There is a plethora of successful US applications to improve membrane separation technologies. However, studies in this field seem to linger at the lab testing phase. This is likely effects and the operation parameters of different membrane processes. The majority of the research in this field utilizes off-shelf US systems not designed for this particular purpose.

Failing to tailor US reactor design and operating conditions to suit process requirements may mislead the evaluation of its true value and capacity. Since some aspects of the US-assisted membrane technology were investigated more extensively than others, we believe it is worth conducting a stocktaking exercise of the research maturity in these aspects as presented in

Table 4. The content of Table 4 was formulated based on the up-to-date literature survey carried out in this study. The level of research maturity of each process aspect was categorized based on the number of studies available into comprehensive, reasonable and insufficient. It appears that among all the identified research aspects, only US power and the use of piezoelectric transducers in ex-situ configuration were studied in an adequate depth. Other aspects such as US frequency, type of feed water and operation mode were explored only in a few studies.

765 Furthermore, most of these studies were focused on treating synthetic feed waters by applying 
expected to produce less vigorous US effects, reducing the risk of membrane damage. High frequency may bring about chemical changes in the membrane surface if it is applied at power level higher than the cavitation threshold. At low power level, high frequency is expected to produce larger number of vibration cycles compared to low frequency, and this might be beneficial especially for the dislodgment of foulants from membrane surface. As such, there is a need to test US-assisted membrane technology with different natural waters (e.g., seawater, groundwater, industrial and municipal wastewaters, etc.) in a high-frequency range of $200 \mathrm{kHz}$ - $1 \mathrm{MHz}$ in different operational modes. Water samples with high ionic strength such as seawater and groundwater were found to enhance ultrasonic effects [190]. They also contain ions such as chloride that could scavenge hydroxyl radicals reducing its possible negative effect on membrane structure.

The use of magneto-strictive transducers, various waveforms, in-situ configuration, large and long-term trials, as well as cost analyses are also hardly investigated. As explained in Section 2, magneto-strictive transducers are more robust and suitable for industrial applications than

781 piezoelectric transducers. Therefore, assessing US application for improving membrane separation performance could also be explored by utilizing this type of transducers. Most of the available US equipment is driven by a sinusoidal wave, while there is a wide range of other forms such as square, triangle and sawtooth that may offer a better choice for US-assisted membrane technology.

Incorporating US technology with membrane filtration processes may increase the capital and operational cost. To justify US applications in membrane filtration processes, there should be a remarkable improvement in the filtration processes, especially in treating low-quality wastewaters laden with contaminants that cause irreversible membrane fouling. Such wastewaters require intensive pre-treatment and frequent membrane cleaning, leading to significant operating costs increase. US application could also be justified to reduce the process 
792 downtime by providing a constant filtration process without interruptions. The cost of US

793 application in water treatment would be justifiable in membrane processes for resources

794 recovery to achieve an elevated recovery rate without membrane fouling or damage.

795 In the future, it would be useful to test different waveforms for membrane performance

796 improvement. Additionally, a process scale-up and proper cost analysis of the long-term

797 experiments covering capital and maintenance expenditures and the return of investment are

798 needed to adequately assess the viability of the US-assisted membrane technology for industrial

799 applications. Several factors affect the US-membrane technology scale-up from laboratory to

800 field, such as type of membrane technology, US method (direct vs indirect sonication), feed

801 water quality, membrane configuration, and purpose of treatment. US technology would be

802 more suitable for treating complex wastewaters containing large amounts of fouling materials

803 that would cause membrane fouling or damage to justify the cost of US installation and use.

804 For instance, industrial wastewaters and concentrated brine are examples of feed waters that

805 require special fouling mitigation measures to avoid membrane fouling or damage. Future work

806 should also investigate the impact of membrane module type on the performance of the US

807 because studies in this field are scarce. Comparison studies will determine the best membrane

808 module for US application, depending on its configuration, materials and packing density.

809 Regarding the scale-up opportunities for US-assisted membrane technology, the authors can

810 offer adjudication informed by literature knowledge and experience in the subject matter. The

811 opportunities for scaling up US-assisted pressure driven membranes lie in pre-treatment and

812 post-cleaning applications. Other configurations of the process (see Figure 4) require high

813 energy to overcome the pressurised environment in the first instance prior to producing any

814 useful effects. This portion of energy can be considered waste as it does not return any benefits

815 to the overall process. The scale up opportunities for other membrane types (e.g. thermally and

816 osmotically driven) are wider. Technically, all systems configurations shown in Figure 4 can 
817 be applied in thermally and osmotically driven membranes as sound waves do not need high

818 energy to breakdown the cohesive forces of the medium. Some of these membrane processes

819 are in the development phase in the present time and this offers a great opportunity for

820 considering the integration of US at early stage of system design.

821 In addition to the aspects mentioned above, it will be worth investigating the effect of US on other emerging processes (e.g. pressure retarded osmosis) and electrochemical processes (e.g. electrodialysis and capacitive deionization), as well as the resistance of novel membrane materials (e.g. graphene, carbon nanotubes, aquaporin, biomimetic).

Table 4: Maturity evaluation of US-assisted membrane technology research.

\begin{tabular}{|c|c|c|c|c|}
\hline \multirow{2}{*}{\multicolumn{2}{|c|}{ Process research aspects }} & \multicolumn{3}{|c|}{ Level of research maturity } \\
\hline & & $\begin{array}{l}\text { Insufficiently } \\
\text { investigated }\end{array}$ & $\begin{array}{l}\text { Reasonably } \\
\text { investigated }\end{array}$ & $\begin{array}{l}\text { Comprehensively } \\
\text { investigated }\end{array}$ \\
\hline \multicolumn{2}{|c|}{ Ultrasonic power } & & & $V$ \\
\hline \multicolumn{2}{|c|}{ Ultrasonic frequency } & & $V$ & \\
\hline \multirow{2}{*}{$\begin{array}{l}\text { Ultrasonic } \\
\text { wave } \\
\text { generation }\end{array}$} & Piezoelectric & & & $V$ \\
\hline & $\begin{array}{l}\text { Magneto- } \\
\text { strictive }\end{array}$ & $V$ & & \\
\hline \multicolumn{2}{|c|}{$\begin{array}{l}\text { Operation mode (pulsed, } \\
\text { continuous and sweep frequency) }\end{array}$} & & $V$ & \\
\hline \multicolumn{2}{|l|}{ Waveform } & $V$ & & \\
\hline \multicolumn{2}{|l|}{ Feedwater type } & & $V$ & \\
\hline \multirow[t]{2}{*}{ Configuration } & In situ & $V$ & & \\
\hline & Ex situ & & & $V$ \\
\hline \multicolumn{2}{|c|}{ Large scale trials } & $V$ & & \\
\hline \multicolumn{2}{|l|}{ Long term trials } & $V$ & & \\
\hline \multicolumn{2}{|c|}{$\begin{array}{l}\text { Proper analysis for capital and } \\
\text { operational cost }\end{array}$} & $V$ & & \\
\hline
\end{tabular}

\section{Conclusions}

829 US coupling with membrane separation technologies has been proposed to reduce fouling and

830 permeate flux increase. The present study reviewed the theoretical and experimental aspects of

831 US technology and links between the US design and membrane system operating parameters 832 and its impact on fouling mitigation and mass and heat transfer enhancements. The efficient 
application of the US requires prior knowledge of the US design and application method and a

834 deep understanding of the nature of the treated solution and its conditions. Overall, US-assisted

835 membrane processes can maintain the filtration processes without interruption and improve the

836 permeate flux substantially. However, technology is still under investigation, and it is energy-

837 intensive with the potential of negatively affecting membrane integrity if the operating 838 conditions are not properly selected.

839 The efficient use of US technology to improve membrane separation seems to be limited to

840 laboratory scale. This is likely due to the high operating cost of US technology and the lack of

841 techno-economic studies on the applications of US technology in membrane filtration

842 processes. A proper cost analysis for the long-term tests on a large scale, considering capital

843 and maintenance costs and the return of investment, is needed to adequately assess the viability

844 of applying the US in combination with membrane technology. Future studies should also focus

845 on investigating the type of membranes' modules suitable for the US technology, type of US

846 application method (direct vs indirect), and on-site natural samples testing. Combining the US

847 with membrane filtration is expected to have a niche market in challenging feed such as 848 industrial and municipal wastewater and brine to justify the technology cost. More research 849 should be done in this field.

\section{$851 \quad$ References}

852 1. Naji, O., et al., Effect of air gap membrane distillation parameters on the removal of fluoride $853 \quad$ from synthetic water. 2018.

8542 2. Ibrar, I., et al., Challenges and potentials of forward osmosis process in the treatment of

855

856

857

858

859

860

861

862 wastewater. Critical Reviews in Environmental Science and Technology, 2019: p. 1-45.

3. Boretti, A. and L. Rosa, Reassessing the projections of the World Water Development Report. npj Clean Water, 2019. 2(1): p. 1-6.

4. Ghaffour, N., et al., Membrane distillation hybrids for water production and energy efficiency enhancement: A critical review. Applied Energy, 2019. 254: p. 113698.

5. Ibrar, I., et al., A review of fouling mechanisms, control strategies and real-time fouling monitoring techniques in forward osmosis. Water, 2019. 11(4): p. 695.

6. Altaee, A., et al., Energy efficiency of hollow fibre membrane module in the forward osmosis seawater desalination process. Journal of Membrane Science, 2019. 587: p. 117165. 
864 7. Ghaffour, N., T.M. Missimer, and G.L. Amy, Technical review and evaluation of the economics

865

866

867

868

869

870

871

872

873

874

875

876

877

878

879

880

881

882

883

884

885

886

887

888

889

890

891

892

893

894

895

896

897

898

899

900

901

902

903

904

905

906

907

908

909

910

911

912

913

914 of water desalination: current and future challenges for better water supply sustainability. Desalination, 2013. 309: p. 197-207.

8. Amy, G., et al., Membrane-based seawater desalination: Present and future prospects. Desalination, 2017. 401: p. 16-21.

9. Lawson, K.W. and D.R. Lloyd, Membrane distillation. Journal of membrane Science, 1997. 124(1): p. 1-25.

10. Khayet, M. and T. Matsuura, Membrane distillation: principles and applications. 2011: Elsevier.

11. Alsaadi, A.S., et al., Modeling of air-gap membrane distillation process: $A$ theoretical and experimental study. Journal of membrane science, 2013. 445: p. 53-65.

12. Curcio, E. and E. Drioli, Membrane distillation and related operations-a review. Separation and Purification Reviews, 2005. 34(1): p. 35-86.

13. El-Bourawi, M., et al., A framework for better understanding membrane distillation separation process. Journal of membrane science, 2006. 285(1-2): p. 4-29.

14. Schofield, R., A. Fane, and C. Fell, Heat and mass transfer in membrane distillation. Journal of membrane Science, 1987. 33(3): p. 299-313.

15. Cath, T.Y., V.D. Adams, and A.E. Childress, Experimental study of desalination using direct contact membrane distillation: a new approach to flux enhancement. Journal of Membrane Science, 2004. 228(1): p. 5-16.

16. Qtaishat, M., et al., Heat and mass transfer analysis in direct contact membrane distillation. Desalination, 2008. 219(1-3): p. 272-292.

17. Gryta, M. and M. Tomaszewska, Heat transport in the membrane distillation process. Journal of membrane science, 1998. 144(1-2): p. 211-222.

18. Alsaadi, A.S., et al., Experimental and theoretical analyses of temperature polarization effect in vacuum membrane distillation. Journal of Membrane Science, 2014. 471: p. 138-148.

19. An, A.K., et al., Enhanced vapor transport in membrane distillation via functionalized carbon nanotubes anchored into electrospun nanofibres. Scientific reports, 2017. 7: p. 41562.

20. Findley, M., Vaporization through porous membranes. Industrial \& Engineering Chemistry Process Design and Development, 1967. 6(2): p. 226-230.

21. Weyl, P.K., Recovery of demineralized water from saline waters. 1967, Google Patents.

22. Flemming, H.-C., et al., Effects and extent of biofilm accumulation in membrane systems. Biofouling and biocorrosion in industrial water systems, 1994: p. 63-89.

23. Lee, J.-G., et al., Total water production capacity inversion phenomenon in multi-stage direct contact membrane distillation: A theoretical study. Journal of membrane science, 2017. 544: p. 126-134.

24. Lamminen, M.O., H.W. Walker, and L.K. Weavers, Mechanisms and factors influencing the ultrasonic cleaning of particle-fouled ceramic membranes. Journal of membrane science, 2004. 237(1-2): p. 213-223.

25. Fortunato, L., et al., Fouling development in direct contact membrane distillation: Non-invasive monitoring and destructive analysis. Water research, 2017.

26. Fortunato, L., et al., Fouling development in direct contact membrane distillation: Non-invasive monitoring and destructive analysis. Water Research, 2018. 132: p. 34-41.

27. Tijing, L.D., et al., Fouling and its control in membrane distillation-A review. Journal of Membrane Science, 2015. 475: p. 215-244.

28. Alklaibi, A.M. and N. Lior, Membrane-distillation desalination: status and potential. Desalination, 2005. 171(2): p. 111-131.

29. Razmjou, A., et al., Superhydrophobic modification of TiO2 nanocomposite PVDF membranes for applications in membrane distillation. Journal of membrane science, 2012. 415: p. 850863.

30. Harvey, N.J., et al., Organic compounds and microbial assessment of a seawater reverse osmosis facility at Tampa Bay Water, USA. Desalination, 2020. 496: p. 114735. 
31. Alnajjar, H., et al., Organic fouling control in reverse osmosis (RO) by effective membrane cleaning using saturated CO2 solution. Separation and Purification Technology, 2021: p. 118410.

32. Kuehn, T., et al., Particle removal from semiconductor wafers by megasonic cleaning. Journal of Aerosol Science, 1996. 27: p. S427-S428.

33. Tarleton, E. and R.J. Wakeman, Microfiltration enhancement by electrical and ultrasonic force fields. Filtration \& Separation, 1990. 27(3): p. 192-194.

34. Chai, X., T. Kobayashi, and N. Fujii, Ultrasound-associated cleaning of polymeric membranes for water treatment. Separation and Purification Technology, 1999. 15(2): p. 139-146.

35. Kyllönen, H., P. Pirkonen, and M. Nyström, Membrane filtration enhanced by ultrasound: a review. Desalination, 2005. 181(1-3): p. 319-335.

36. Muthukumaran, S., et al., Application of ultrasound in membrane separation processes: a review. Reviews in chemical engineering, 2006. 22(3): p. 155-194.

37. Hou, D., et al., An ultrasonic assisted direct contact membrane distillation hybrid process for desalination. Journal of Membrane Science, 2015. 476: p. 59-67.

38. Hou, D., et al., Ultrasonic irradiation control of silica fouling during membrane distillation process. Desalination, 2016. 386: p. 48-57.

39. Naji, O., et al., Direct contact ultrasound for fouling control and flux enhancement in Air-Gap Membrane Distillation. Ultrasonics Sonochemistry, 2019: p. 104816.

40. Naji, O.A., Evaluation of sonically enhanced AGMD for industrial scale water treatment. 2019, University of Southern Queensland.

41. Guillén-Burrieza, E., et al., Experimental analysis of an air gap membrane distillation solar desalination pilot system. Journal of Membrane Science, 2011. 379(1-2): p. 386-396.

42. Thomas, N., et al., Comparative assessment of the effects of 3D printed feed spacers on process performance in MD systems. Desalination, 2021. 503: p. 114940.

43. Chen, D., et al., Sonochemical reactions of dissolved organic matter. Research on chemical intermediates, 2004. 30(7): p. 735-753.

44. Al-juboori, R.A., et al., Power effect of ultrasonically vibrated spacers in air gap membrane distillation: Theoretical and experimental investigations. Separation and Purification Technology, 2021. 262: p. 118319.

45. Al-Juboori, R.A. and L. Bowtell, Ultrasound Technology Integration into Drinking Water Treatment Train, in Sonochemical Reactions. 2019, IntechOpen.

46. Chen, D., et al., Sonochemical reactions of dissolved organic matter. Research on chemical intermediates, 2004. 30(7-8): p. 735-753.

47. Tsukamoto, I., et al., Inactivation of Saccharomyces cerevisiae by ultrasonic irradiation. Ultrasonics sonochemistry, 2004. 11(2): p. 61-65.

48. Gogate, P.R. and A.M. Kabadi, A review of applications of cavitation in biochemical engineering/biotechnology. Biochemical Engineering Journal, 2009. 44(1): p. 60-72.

49. Yusaf, T. and R.A. Al-Juboori, Alternative methods of microorganism disruption for agricultural applications. Applied energy, 2014. 114: p. 909-923.

50. Naddeo, V., et al., Water and wastewater disinfection by ultrasound irradiation-a critical review. Global NEST Journal, 2014. 16(3): p. 561-577.

51. Kallioinen, M. and M. Mänttäri, Influence of ultrasonic treatment on various membrane materials: a review. Separation Science and Technology, 2011. 46(9): p. 1388-1395.

52. Qasim, M., et al., The use of ultrasound to mitigate membrane fouling in desalination and water treatment. Desalination, 2018. 443: p. 143-164.

53. Zhang, R., et al., Study on ultrasonic techniques for enhancing the separation process of membrane. Ultrasonics sonochemistry, 2019. 55: p. 341-347.

54. Arefi-Oskoui, S., et al., A review on the applications of ultrasonic technology in membrane bioreactors. Ultrasonics sonochemistry, 2019. 58: p. 104633.

55. Young, F.R., Cavitation. 1999: World Scientific. 
56. Al-Juboori, R. and T. Yusaf. Improving the performance of ultrasonic horn reactor for deactivating microorganisms in water. in IOP Conference Series: Materials Science and Engineering. 2012. IOP Publishing.

57. Luther, S., et al., Observation of acoustic cavitation bubbles at 2250 frames per second. Ultrasonics Sonochemistry, 2001. 8(3): p. 159-162.

58. Laborde, J.L., et al., Acoustic bubble cavitation at low frequencies. Ultrasonics, 1998. 36(1-5): p. 589-594.

59. Qasim, M., et al., The use of ultrasound to mitigate membrane fouling in desalination and water treatment. Desalination, 2018. 443: p. 143-164.

60. Costalonga, M., P. Brunet, and H. Peerhossaini, Low frequency vibration induced streaming in a Hele-Shaw cell. Physics of Fluids, 2015. 27(1): p. 013101.

61. Al-Juboori, R.A. and T. Yusaf, Identifying the optimum process parameters for ultrasonic cellular disruption of E. coli. International Journal of Chemical Reactor Engineering, 2012. 10(1).

62. Thompson, L.H. and L. Doraiswamy, Sonochemistry: science and engineering. Industrial \& Engineering Chemistry Research, 1999. 38(4): p. 1215-1249.

63. Rooze, J., et al., Dissolved gas and ultrasonic cavitation-a review. Ultrasonics sonochemistry, 2013. 20(1): p. 1-11.

64. Rybkin, K., et al. Experimental study of formation and dynamics of cavitation bubbles and acoustic flows in $\mathrm{NaCl}, \mathrm{KCl}$ water solutions. in Journal of Physics: Conference Series. 2017. IOP Publishing.

65. Sharma, S.K., D. Chen, and A. Mudhoo, Handbook on applications of ultrasound: sonochemistry for sustainability. 2011: CRC press.

66. Hoyos, M. and A. Castro, Controlling the acoustic streaming by pulsed ultrasounds. Ultrasonics, 2013. 53(1): p. 70-76.

67. Mirzaie, A. and T. Mohammadi, Effect of ultrasonic waves on flux enhancement in microfiltration of milk. Journal of Food Engineering, 2012. 108(1): p. 77-86.

68. Shahraki, M.H., A. Maskooki, and A. Faezian, Effect of various sonication modes on permeation flux in cross flow ultrafiltration membrane. Journal of Environmental Chemical Engineering, 2014. 2(4): p. 2289-2294.

69. Al-Juboori, R.A., et al., Insights into the scalability of magnetostrictive ultrasound technology for water treatment applications. Ultrasonics sonochemistry, 2016. 28: p. 357-366.

70. Kerboua, K. and O. Hamdaoui, Insights into numerical simulation of controlled ultrasonic waveforms driving single cavitation bubble activity. Ultrasonics sonochemistry, 2018. 43: p. 237-247.

71. Ramezanianpour, M. and M. Sivakumar, An analytical flux decline model for membrane distillation. Desalination, 2014. 345: p. 1-12.

72. Altmann, J. and S. Ripperger, Particle deposition and layer formation at the crossflow microfiltration. Journal of Membrane Science, 1997. 124(1): p. 119-128.

73. Trujillo, F.J. and K. Knoerzer, A computational modeling approach of the jet-like acoustic streaming and heat generation induced by low frequency high power ultrasonic horn reactors. Ultrasonics Sonochemistry, 2011. 18(6): p. 1263-1273.

74. Zhang, J., L. Zhang, and J. Deng, Numerical study of the collapse of multiple bubbles and the energy conversion during bubble collapse. Water, 2019. 11(2): p. 247.

75. Tang, X. and D. Staack, Bioinspired mechanical device generates plasma in water via cavitation. Science advances, 2019. 5(3): p. eaau7765.

76. Wan, M.-W., et al., Effect of coagulation mechanisms on the fouling and ultrasonic cleaning of PTFE membrane. Water Science and Technology, 2012. 66(11): p. 2291-2298.

77. Zhu, C. and G. Liu, Modeling of ultrasonic enhancement on membrane distillation. Journal of Membrane Science, 2000. 176(1): p. 31-41. 
78. Phattaranawik, J., R. Jiraratananon, and A. Fane, Effect of pore size distribution and air flux on mass transport in direct contact membrane distillation. Journal of Membrane Science, 2003. 215(1-2): p. 75-85.

79. Thombre, N.V., et al., Ultrasound induced cleaning of polymeric nanofiltration membranes. Ultrasonics sonochemistry, 2020. 62: p. 104891.

80. Sanderson, R., et al., Ultrasonic time-domain reflectometry as a non-destructive instrumental visualization technique to monitor inorganic fouling and cleaning on reverse osmosis membranes. Journal of membrane science, 2002. 207(1): p. 105-117.

81. Maskooki, A., et al., Effect of low frequencies and mixed wave of ultrasound and EDTA on flux recovery and cleaning of microfiltration membranes. Separation and Purification Technology, 2008. 59(1): p. 67-73.

82. Alardhi, S.M., T.M. Albayati, and J.M. Alrubaye, A hybrid adsorption membrane process for removal of dye from synthetic and actual wastewater. Chemical Engineering and ProcessingProcess Intensification, 2020. 157: p. 108113.

83. Secondes, M.F.N., et al., Removal of emerging contaminants by simultaneous application of membrane ultrafiltration, activated carbon adsorption, and ultrasound irradiation. Journal of hazardous materials, 2014. 264: p. 342-349.

84. Kadhum, S., G. Alkindi, and T. Albayati, Remediation of phenolic wastewater implementing nano zerovalent iron as a granular third electrode in an electrochemical reactor. International Journal of Environmental Science and Technology, 2021: p. 1-10.

85. Zheng, J., et al., Development of an electrochemical ceramic membrane filtration system for efficient contaminant removal from waters. Environmental science \& technology, 2018. 52(7): p. 4117-4126.

86. Zhang, M., et al., Ultrasound-assisted electrochemical treatment for phenolic wastewater. Ultrasonics sonochemistry, 2020. 65: p. 105058.

87. Foroughi, F., et al., Sonochemical and Sonoelectrochemical Production of Energy Materials. Catalysts, 2021. 11(2): p. 284.

88. Mao, H., et al., High-performance self-cleaning piezoelectric membrane integrated with in-situ ultrasound for wastewater treatment. Journal of the European Ceramic Society, 2020. 40(10): p. 3632-3641.

89. Tran, T., et al., Ultrasound enhancement of microfiltration performance for natural organic matter removal. Organic Geochemistry, 2007. 38(7): p. 1091-1096.

90. Kobayashi, T., et al., Ultrasound-enhanced membrane-cleaning processes applied water treatments: influence of sonic frequency on filtration treatments. Ultrasonics, 2003. 41(3): p. 185-190.

91. Wang, X.-I., et al., Effect of ultrasound irradiation on polymeric microfiltration membranes. Desalination, 2005. 175(2): p. 187-196.

92. Latt, K.K. and T. Kobayashi, Ultrasound-membrane hybrid processes for enhancement of filtration properties. Ultrasonics sonochemistry, 2006. 13(4): p. 321-328.

93. Chen, D., L.K. Weavers, and H.W. Walker, Ultrasonic control of ceramic membrane fouling by particles: effect of ultrasonic factors. Ultrasonics sonochemistry, 2006. 13(5): p. 379-387.

94. Li, J., R. Sanderson, and E. Jacobs, Ultrasonic cleaning of nylon microfiltration membranes fouled by Kraft paper mill effluent. Journal of Membrane Science, 2002. 205(1-2): p. 247-257.

95. Rocha, I., J. Marques, and A. Silva, Effects of ultrasound on the performance improvement of wastewater microfiltration through a porous ceramic filter. Brazilian journal of chemical engineering, 2009. 26: p. 641-648.

96. Hakata, Y., F. Roddick, and L. Fan, Impact of ultrasonic pre-treatment on the microfiltration of a biologically treated municipal effluent. Desalination, 2011. 283: p. 75-79.

97. Matsumoto, Y., et al., Improvement of membrane permeation performance by ultrasonic microfiltration. Journal of chemical engineering of Japan, 1996. 29(4): p. 561-567. 
1066

1067

1068

1069

1070

1071

1072

1073

1074

1075

1076

1077

1078

1079

1080

1081

1082

1083

1084

1085

1086

1087

1088

1089

1090

1091

1092

1093

1094

1095

1096

1097

1098

1099

1100

1101

1102

1103

1104

1105

1106

1107

1108

1109

1110

1111

1112

1113

1114
98. Azami, S. and M. Amirinejad, Effect of Ultrasonication on Membrane Structure and Flux Recovery for Whey Ultrafiltration. Journal of Membrane Science and Research, 2019. 5(4): p. 261-267.

99. Liu, D., et al., Comparative study of ultrasound-assisted and conventional stirred dead-end microfiltration of grape pomace extracts. Ultrasonics sonochemistry, 2013. 20(2): p. 708-714.

100. Alventosa-deLara, E., et al., Study and optimization of the ultrasound-enhanced cleaning of an ultrafiltration ceramic membrane through a combined experimental-statistical approach. Ultrasonics sonochemistry, 2014. 21(3): p. 1222-1234.

101. Borea, L., et al., Wastewater treatment by membrane ultrafiltration enhanced with ultrasound: Effect of membrane flux and ultrasonic frequency. Ultrasonics, 2018. 83: p. 42-47.

102. Cai, M., et al., Effects of ultrasound on ultrafiltration of Radix astragalus extract and cleaning of fouled membrane. Separation and purification technology, 2009. 68(3): p. 351-356.

103. Cai, M., S. Wang, and H.-h. Liang, Optimization of ultrasound-assisted ultrafiltration of Radix astragalus extracts with hollow fiber membrane using response surface methodology. Separation and purification technology, 2012. 100: p. 74-81.

104. Chai, X., T. Kobayashi, and N. Fujii, Ultrasound effect on cross-flow filtration of polyacrylonitrile ultrafiltration membranes. Journal of Membrane Science, 1998. 148(1): p. 129-135.

105. Cai, M., S. Zhao, and H. Liang, Mechanisms for the enhancement of ultrafiltration and membrane cleaning by different ultrasonic frequencies. Desalination, 2010. 263(1-3): p. 133138.

106. Muthukumaran, S., et al., The optimisation of ultrasonic cleaning procedures for dairy fouled ultrafiltration membranes. Ultrasonics Sonochemistry, 2005. 12(1-2): p. 29-35.

107. Naddeo, V., L. Borea, and V. Belgiorno, Sonochemical control of fouling formation in membrane ultrafiltration of wastewater: effect of ultrasonic frequency. Journal of water process engineering, 2015. 8: p. e92-e97.

108. Kobayashi, T., X. Chai, and N. Fujii, Ultrasound enhanced cross-flow membrane filtration. Separation and Purification Technology, 1999. 17(1): p. 31-40.

109. Juang, R.-S. and K.-H. Lin, Flux recovery in the ultrafiltration of suspended solutions with ultrasound. Journal of Membrane Science, 2004. 243(1-2): p. 115-124.

110. Naddeo, V., et al., Removal of contaminants of emerging concern from real wastewater by an innovative hybrid membrane process-UltraSound, Adsorption, and Membrane ultrafiltration (USAMe ${ }^{\circledR}$ ). Ultrasonics Sonochemistry, 2020. 68: p. 105237.

111. Patel, T.M. and K. Nath, Alleviation of flux decline in cross flow nanofiltration of twocomponent dye and salt mixture by low frequency ultrasonic irradiation. Desalination, 2013. 317: p. 132-141.

112. Wang, J., et al., Ultrasonic-assisted acid cleaning of nanofiltration membranes fouled by inorganic scales in arsenic-rich brackish water. Desalination, 2016. 377: p. 172-177.

113. Liu, Q., et al., Ultrasonic-intensified chemical cleaning of nano filtration membranes in oilfield sewage purification systems. Journal of Engineered Fibers and Fabrics, 2016. 11(2): p. 155892501601100203.

114. Feng, v.D., J. Van Deventer, and C. Aldrich, Ultrasonic defouling of reverse osmosis membranes used to treat wastewater effluents. Separation and Purification Technology, 2006. 50(3): p. 318-323.

115. Li, Y.-S., et al., Cleaning effects of oxalic acid under ultrasound to the used reverse osmosis membranes with an online cleaning and monitoring system. Desalination, 2016. 390: p. 62-71.

116. Al-Juboori, R.A., T. Yusaf, and V. Aravinthan, Investigating the efficiency of thermosonication for controlling biofouling in batch membrane systems. Desalination, 2012. 286: p. 349-357.

117. García-Fayos, B., et al., Study of ultrasonically enhanced chemical cleaning of SWRO membranes at pilot plant scale. Desalination and Water Treatment, 2017. 88: p. 1-7. 
1115

1116

1117

1118

1119

1120

1121

1122

1123

1124

1125

1126

1127

1128

1129

1130

1131

1132

1133

1134

1135

1136

1137

1138

1139

1140

1141

1142

1143

1144

1145

1146

1147

1148

1149

1150

1151

1152

1153

1154

1155

1156

1157

1158

1159

1160

1161

1162

1163

1164

1165

118. Susanto, H. and M. Ulbricht, Characteristics, performance and stability of polyethersulfone ultrafiltration membranes prepared by phase separation method using different macromolecular additives. Journal of Membrane Science, 2009. 327(1-2): p. 125-135.

119. Žabková, M., E.B. da Silva, and A. Rodrigues, Recovery of vanillin from lignin/vanillin mixture by using tubular ceramic ultrafiltration membranes. Journal of membrane science, 2007. 301(1-2): p. 221-237.

120. Lee, H., et al., Cleaning strategies for flux recovery of an ultrafiltration membrane fouled by natural organic matter. Water research, 2001. 35(14): p. 3301-3308.

121. Shi, X., et al., Fouling and cleaning of ultrafiltration membranes: a review. Journal of Water Process Engineering, 2014. 1: p. 121-138.

122. Boley, A., et al., Ceramic membrane ultrafiltration of natural surface water with ultrasound enhanced backwashing. Water Science and Technology, 2010. 61(5): p. 1121-1127.

123. Li, X., J. Yu, and A.A. Nnanna, Fouling mitigation for hollow-fiber UF membrane by sonication. Desalination, 2011. 281: p. 23-29.

124. Muthukumaran, S., et al., Mechanisms for the ultrasonic enhancement of dairy whey ultrafiltration. Journal of membrane science, 2005. 258(1-2): p. 106-114.

125. Yu, W., N. Graham, and T. Liu, Effect of intermittent ultrasound on controlling membrane fouling with coagulation pre-treatment: Significance of the nature of adsorbed organic matter. Journal of Membrane Science, 2017. 535: p. 168-177.

126. Chen, D., L.K. Weavers, and H.W. Walker, Ultrasonic control of ceramic membrane fouling: effect of particle characteristics. Water research, 2006. 40(4): p. 840-850.

127. Hengl, N., et al., A new way to apply ultrasound in cross-flow ultrafiltration: Application to colloidal suspensions. Ultrasonics sonochemistry, 2014. 21(3): p. 1018-1025.

128. Mackley, M. and N. Sherman, Cross-flow cake filtration mechanisms and kinetics. Chemical engineering science, 1992. 47(12): p. 3067-3084.

129. Naddeo, V., et al., Control of fouling formation in membrane ultrafiltration by ultrasound irradiation. Environmental technology, 2015. 36(10): p. 1299-1307.

130. Qin, J.-J., et al., Development of novel backwash cleaning technique for reverse osmosis in reclamation of secondary effluent. Journal of membrane science, 2010. 346(1): p. 8-14.

131. Lu, J.-y., X. Du, and G. Lipscomb. Cleaning membranes with focused ultrasound beams for drinking water treatment. in 2009 IEEE International Ultrasonics Symposium. 2009. IEEE.

132. Wang, J., et al., Enhancing antibiofouling performance of Polysulfone (PSf) membrane by photo-grafting of capsaicin derivative and acrylic acid. Applied surface science, 2014. 317: p. 210-219.

133. Simon, A., et al., Low-frequency ultrasound to improve dead-end ultrafiltration performance. Separation Science and Technology, 2000. 35(16): p. 2619-2637.

134. Muthukumaran, S., et al., The use of ultrasonic cleaning for ultrafiltration membranes in the dairy industry. Separation and Purification Technology, 2004. 39(1-2): p. 99-107.

135. Rabelo, R.S., et al., Ultrasound assisted extraction and nanofiltration of phenolic compounds from artichoke solid wastes. Journal of food engineering, 2016. 178: p. 170-180.

136. Li, S., X. Weihong, and X. Nanping, Effect of ultrasound on the treatment of emulsification wastewater by ceramic membranes. Chinese Journal of Chemical Engineering, 2007. 15(6): p. 855-860.

137. Prihasto, N., Q.-F. Liu, and S.-H. Kim, Pre-treatment strategies for seawater desalination by reverse osmosis system. Desalination, 2009. 249(1): p. 308-316.

138. Chen, K.L., et al., The development of membrane fouling in full-scale RO processes. Journal of Membrane Science, 2004. 232(1-2): p. 63-72.

139. $\mathrm{Xu}, \mathrm{P}$., et al., Effect of membrane fouling on transport of organic contaminants in NF/RO membrane applications. Journal of Membrane Science, 2006. 279(1-2): p. 165-175.

140. Shih, M.-C., An overview of arsenic removal by pressure-drivenmembrane processes. Desalination, 2005. 172(1): p. 85-97. 
1166

1167

1168

1169

1170

1171

1172

1173

1174

1175

1176

1177

1178

1179

1180

1181

1182

1183

1184

1185

1186

1187

1188

1189

1190

1191

1192

1193

1194

1195

1196

1197

1198

1199

1200

1201

1202

1203

1204

1205

1206

1207

1208

1209

1210

1211

1212

1213

1214

141. Jiao, B., A. Cassano, and E. Drioli, Recent advances on membrane processes for the concentration of fruit juices: a review. Journal of food engineering, 2004. 63(3): p. 303-324.

142. Mairal, A.P., A.R. Greenberg, and W.B. Krantz, Investigation of membrane fouling and cleaning using ultrasonic time-domain reflectometry. Desalination, 2000. 130(1): p. 45-60.

143. Kronenberg, K., Magnetic water treatment de-mystified, http. 1998.

144. Harvey, R.F., Cavitational reverse osmotic separation of water from saline solutions. 1965, Google Patents.

145. Al-juboori, R.A., Ultrasound technology as a pre-treatment for biofouling control in Reverse Osmosis (RO) system. 2012, University of Southern Queensland.

146. Goswami, L., et al., Membrane bioreactor and integrated membrane bioreactor systems for micropollutant removal from wastewater: A review. Journal of water process engineering, 2018. 26: p. 314-328.

147. Khan, M.A., et al., Can membrane bioreactor be a smart option for water treatment? Bioresource Technology Reports, 2018. 4: p. 80-87.

148. Jegatheesan, V., et al., Treatment of textile wastewater with membrane bioreactor: a critical review. Bioresource technology, 2016. 204: p. 202-212.

149. Galinha, C.F., S. Sanches, and J.G. Crespo, Membrane bioreactors, in Fundamental Modelling of Membrane Systems. 2018, Elsevier. p. 209-249.

150. Jia, S., et al., Advanced treatment of biologically pretreated coal gasification wastewater by a novel integration of catalytic ultrasound oxidation and membrane bioreactor. Bioresource technology, 2015. 189: p. 426-429.

151. Jiang, W., et al., Effect of quorum quenching on the reactor performance, biofouling and biomass characteristics in membrane bioreactors. Water research, 2013. 47(1): p. 187-196.

152. Pendashteh, A.R., et al., Membrane foulants characterization in a membrane bioreactor (MBR) treating hypersaline oily wastewater. Chemical Engineering Journal, 2011. 168(1): p. 140-150.

153. $\mathrm{Xu}, \mathrm{M}$., et al., Mechanisms of membrane fouling controlled by online ultrasound in an anaerobic membrane bioreactor for digestion of waste activated sludge. Journal of membrane science, 2013. 445: p. 119-126.

154. Sui, P., X. Wen, and X. Huang, Feasibility of employing ultrasound for on-line membrane fouling control in an anaerobic membrane bioreactor. Desalination, 2008. 219(1-3): p. 203-213.

155. Ruiz, L., et al., Ultrasonic irradiation for ultrafiltration membrane cleaning in MBR systems: operational conditions and consequences. Water Science and Technology, 2017. 75(4): p. 802812.

156. Ruiz, L., et al., Analysis of the effects of ultrasound irradiation over effluent quality and membrane integrity in flat sheet microfiltration MBR systems. Desalination and Water Treatment, 2015. 56(13): p. 3576-3589.

157. Arefi-Oskoui, S., et al., A review on the applications of ultrasonic technology in membrane bioreactors. Ultrasonics sonochemistry, 2019: p. 104633.

158. Li, D., et al., Optimization of the operating parameters for online ultrasonic on controlling membrane fouling in SMBR. Desalination and Water Treatment, 2013. 51(19-21): p. 38323839.

159. Sui, P., X. Wen, and X. Huang, Membrane fouling control by ultrasound in an anaerobic membrane bioreactor. Frontiers of Environmental Science \& Engineering in China, 2007. 1(3): p. 362-367.

160. Abdurahman, N. and N. Azhari, Performance of ultrasonic membrane anaerobic system (UMAS) in membrane fouling control. Int. J. Eng. Sci. Innovative Tech., 2013. 2.

161. Shafie, N., et al., The performance study of Ultrasonic-assisted Membrane Anaerobic System (UMAS) for Chemical Oxygen Demand (COD) removal efficiency and methane gas production in Palm Oil Mill Effluent (POME) treatment. 2016. 
162. Liu, H., et al., Enhancement of organic pollutant biodegradation by ultrasound irradiation in a biological activated carbon membrane reactor. Process Biochemistry, 2005. 40(9): p. 30023007.

163. Yoon, S.-H., H.-S. Kim, and S. Lee, Incorporation of ultrasonic cell disintegration into a membrane bioreactor for zero sludge production. Process Biochemistry, 2004. 39(12): p. 19231929.

164. Joshi, P. and W. Parker, Effect of pretreatment using ultrasound and hydrogen peroxide on digestion of waste activated sludge in an anaerobic membrane bioreactor. Environmental Progress \& Sustainable Energy, 2015. 34(6): p. 1724-1730.

165. Wu, S., et al., Evaluating the excess sludge reduction in activated sludge system with ultrasonic treatment. Water Science and Technology, 2018. 77(9): p. 2341-2347.

166. Prado, M., et al., Removal of emerging contaminant and fouling control in membrane bioreactors by combined ozonation and sonolysis. International Biodeterioration \& Biodegradation, 2017. 119: p. 577-586.

167. Gray, G.T., J.R. McCutcheon, and M. Elimelech, Internal concentration polarization in forward osmosis: role of membrane orientation. Desalination, 2006. 197(1-3): p. 1-8.

168. Heikkinen, J., et al., Ultrasound-assisted forward osmosis for mitigating internal concentration polarization. Journal of Membrane Science, 2017. 528: p. 147-154.

169. Choi, Y.-J., et al., Application of ultrasound to mitigate calcium sulfate scaling and colloidal fouling. Desalination, 2014. 336: p. 153-159.

170. Chanukya, B. and N.K. Rastogi, Ultrasound assisted forward osmosis concentration of fruit juice and natural colorant. Ultrasonics sonochemistry, 2017. 34: p. 426-435.

171. Choi, Y., et al., The use of ultrasound to reduce internal concentration polarization in forward osmosis. Ultrasonics sonochemistry, 2018. 41: p. 475-483.

172. Wang, Q., et al., Combined water flux enhancement of PES-based TFC membranes in ultrasonic-assisted forward osmosis processes. Journal of Industrial and Engineering Chemistry, 2018. 64: p. 266-275.

173. Lee, S., H.K. Shon, and S. Hong, Dewatering of activated sludge by forward osmosis (FO) with ultrasound for fouling control. Desalination, 2017. 421: p. 79-88.

174. Nguyen, N.C., et al., Application of forward osmosis (FO) under ultrasonication on sludge thickening of waste activated sludge. Water Science and Technology, 2015. 72(8): p. 13011307.

175. Kesieme, U.K., et al., Recovery of water and acid from leach solutions using direct contact membrane distillation. Water science and technology, 2014. 69(4): p. 868-875.

176. Gálvez, J.B., L. García-Rodríguez, and I. Martín-Mateos, Seawater desalination by an innovative solar-powered membrane distillation system: the MEDESOL project. Desalination, 2009. 246(1-3): p. 567-576.

177. Susanto, H., Towards practical implementations of membrane distillation. Chemical Engineering and Processing: Process Intensification, 2011. 50(2): p. 139-150.

178. Meindersma, G., C. Guijt, and A. De Haan, Desalination and water recycling by air gap membrane distillation. Desalination, 2006. 187(1-3): p. 291-301.

179. Chernyshov, M., G. Meindersma, and A. De Haan, Comparison of spacers for temperature polarization reduction in air gap membrane distillation. Desalination, 2005. 183(1-3): p. 363374.

180. Zhu, C., et al., Ultrasonic stimulation on enhancement of air gap membrane distillation. Journal of membrane science, 1999. 161(1-2): p. 85-93.

181. Gryta, M. and M. Barancewicz, Influence of morphology of PVDF capillary membranes on the performance of direct contact membrane distillation. Journal of Membrane Science, 2010. 358(1-2): p. 158-167.

182. Hou, D., et al., Ultrasonic assisted direct contact membrane distillation hybrid process for membrane scaling mitigation. Desalination, 2015. 375: p. 33-39. 
183. Hou, D., et al., Humic acid fouling mitigation by ultrasonic irradiation in membrane distillation process. Separation and Purification Technology, 2015. 154: p. 328-337.

184. Chafidz, A., et al., Portable and integrated solar-driven desalination system using membrane distillation for arid remote areas in Saudi Arabia. Desalination, 2014. 345: p. 36-49.

185. Martinetti, C.R., A.E. Childress, and T.Y. Cath, High recovery of concentrated RO brines using forward osmosis and membrane distillation. Journal of membrane science, 2009. 331(1-2): p. 31-39.

186. El-Zanati, E. and K. El-Khatib, Integrated membrane-based desalination system. Desalination, 2007. 205(1-3): p. 15-25.

187. Masselin, l., et al., Effect of sonication on polymeric membranes. Journal of membrane science, 2001. 181(2): p. 213-220.

188. Kinumoto, T., et al., Durability of perfluorinated ionomer membrane against hydrogen peroxide. Journal of power Sources, 2006. 158(2): p. 1222-1228.

189. Nemani, S.K., et al., Surface modification of polymers: methods and applications. Advanced Materials Interfaces, 2018. 5(24): p. 1801247.

190. Wakeford, C., R. Blackburn, and P. Lickiss, Effect of ionic strength on the acoustic generation of nitrite, nitrate and hydrogen peroxide. Ultrasonics Sonochemistry, 1999. 6(3): p. 141-148. 